\title{
The Selenoprotein Glutathione Peroxidase 4: From Molecular Mechanisms to Novel Therapeutic Opportunities
}

\author{
Kamari Weaver ${ }^{1}$, and Rachid Skouta ${ }^{1, *}$ \\ 1 Department of Biology, University of Massachusetts, Amherst, MA 01003, USA \\ * Correspondence: rskouta@umass.edu; Tel.: +1-413-577-4167
}

\begin{abstract}
The selenoprotein glutathione peroxidase 4 (GPX4) is one of the main antioxidant mediators in the human body. Its central function involves the reduction of complex hydroperoxides into their respective alcohols often using reduced Glutathione (GSH) as a reducing agent. GPX4 has become a hotspot therapeutic target in biomedical research following its characterization as a chief regulator of ferroptosis, and its subsequent recognition as a specific pharmacological target for the treatment of an extensive variety of human diseases including cancers and neurodegenerative disorders. Several recent studies have provided insights into how GPX4 is distinguished from the rest of the glutathione peroxidase family, the unique biochemical properties of GPX4, how GPX4 is related to lipid peroxidation and ferroptosis, and how the enzyme may be modulated as a potential therapeutic target. This current report aims to review the literature underlying all these insights and present an up-to-date perspective on the current understanding of GPX4 as a potential therapeutic target.
\end{abstract}

Keywords: Selenoprotein Glutathione Peroxidase 4 (GPX4); Reduced Glutathione (GSH); ferroptosis; lipid peroxidation; ferroptosis modulators; small molecules targeting GPX4.

\section{Introduction}

In this review, we summarize recent advances in our understanding of the phospholipid repair enzyme GPX4. We examine the molecular mechanisms of GPX4-mediated oxidative regulation, and its potential for therapeutic applications in human diseases. To capture the growing landscape of GPX4 biology and its impact as a therapeutic target, where appropriate, we refer readers to recent reviews for a more detailed discussion.

\section{Glutathione Peroxidase Family}

\subsection{The Origins of Glutathione Peroxidase}

Glutathione peroxidases (GPXs) constitute an interesting family of phylogenetically related oxidoreductases observed in all living organisms. This family is a central component of the cellular antioxidant defense system. GPX activity was first detected in 1952, when G.C Mills and colleagues observed its activity in protecting hemoglobin from oxidative breakdown [1]. In the 1960s, GPX activity was noticed in other tissues, including the lungs and kidneys, and shown to reduce hydroperoxide-type compounds including $\mathrm{H}_{2} \mathrm{O}_{2}$ [2,3]. In the 1970s, the biochemical properties were characterized for GPX, and importantly, elemental selenium was discovered to play a key role in enzymatic activity [47]. This enzyme is known today as GPX1, and it is recognized as the most efficient peroxide removal system in the cytosol of many mammalian cells [8]. GPx-1 was the only GPx known until the 1980s. The list of mammalian GPxs has since grown up to eight, 
numbered one-through-eight. An intensive study on the evolutionary history of the GPx family was recently reviewed [9]. The GPX family is well established today as one of the main antioxidant systems. Accordingly, they have the essential function to reduce reactive oxygen species (ROS), such as hydroperoxides, into their respective alcohols often using glutathione as a cofactor $[10,11]$. In addition to their role in maintaining oxidative homeostasis, many GPx enzymes are also involved in the posttranslational modification of proteins, signaling pathways, among several other biological processes [12]. There is considerable diversity among GPX enzymes regarding their biological relevance, structure, and presence of a selenocysteine residue (Table 1 and Table 2).

Table 1. Biochemical Features and Biological Relevance of GPX family

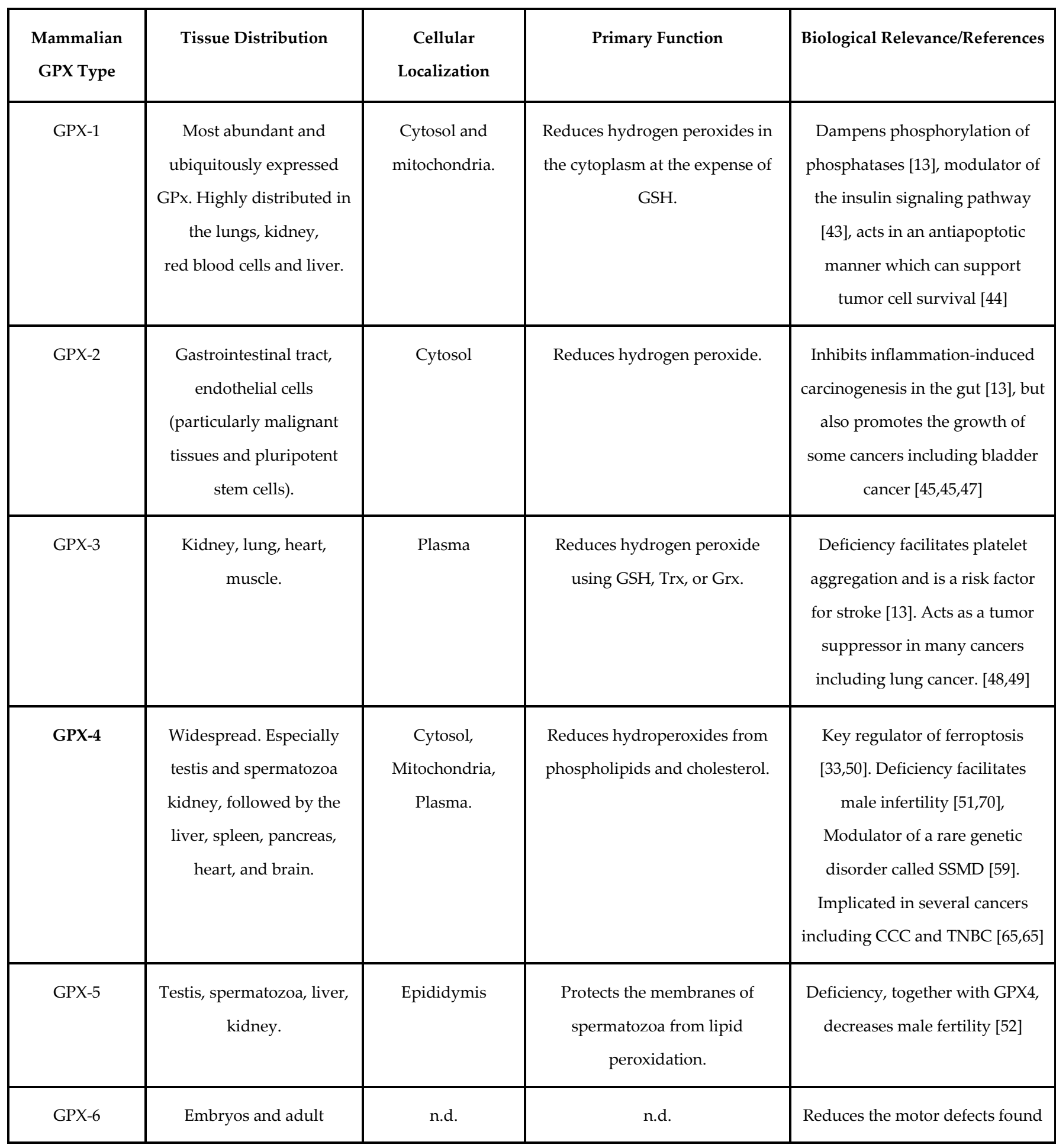




\begin{tabular}{|c|c|c|c|c|}
\hline & olfactory epithelium. & & & in Huntinhton's disease [53] \\
\hline GPX-7 & Endoplasmic reticulum & n.d. & $\begin{array}{l}\text { Mild glutathione peroxidase } \\
\text { activity. Senses ROS levels and } \\
\text { transmits redox signals to other } \\
\text { thiols. }\end{array}$ & $\begin{array}{l}\text { Contributes to oxidative protein } \\
\text { folding in the ER. }[54,55]\end{array}$ \\
\hline GPX-8 & Endoplasmic reticulum & n.d. & $\begin{array}{l}\text { Mild glutathione peroxidase } \\
\text { activity. Prevents endoplasmic } \\
\text { reticulum oxidation and stress. }\end{array}$ & $\begin{array}{l}\text { Contributes to oxidative protein } \\
\text { folding in the ER. } \\
{[54,55]}\end{array}$ \\
\hline
\end{tabular}

Abbreviations: CCC: Clear-cell carcinoma, TNBC: Triple Negative Breast Cancer, Trx: thioredoxin, Grx: glutaredoxin; GSH: glutathione, ER: endoplasmic reticulum; n.d.: not discovered, SSMD: Sedaghatian-type Spondylometaphyseal Dysplasia, p53: tumor-suppressor protein.

Table 2. Structural Features of Glutathione Peroxidase

\begin{tabular}{|c|c|c|c|c|c|c|}
\hline $\begin{array}{c}\text { Mammalian } \\
\text { GPX Type }\end{array}$ & Peroxidic Residue & $\begin{array}{c}\text { Uniprot } \\
\text { Molecular } \\
\text { Weight } \\
\text { (kDa) }\end{array}$ & Structure Type & $\begin{array}{l}\text { Human Wild- } \\
\text { Type Crystal } \\
\text { Structure } \\
\text { (PDB Code) }\end{array}$ & $\begin{array}{l}\text { Human Mutant } \\
\text { Crystal Structure } \\
\text { (PDB Code) }\end{array}$ & $\begin{array}{c}\text { Reference } \\
\text { (Uniprot } \\
\text { Code) }\end{array}$ \\
\hline GPX-1 & Selenocysteine & 22 & Homotetramer & n.d. & U46G (2F8A) & P07203 \\
\hline GPX-2 & Selenocysteine & 21.9 & Homotetramer & n.d. & U46C (2HE3) & P18283 \\
\hline GPX-3 & Selenocystine & 22.5 & Homotetramer & n.d. & U46G (2R37) & P22352 \\
\hline GPX-4 & Selenocysteine & 22 & Monomer & $6 \mathrm{ElW}$ & $\begin{array}{c}\text { Many mutants (e.g., } \\
\text { 7L81, 6HN3, 7L8K, } \\
\text { etc.) }\end{array}$ & P36969 \\
\hline GPX-5 & Cysteine & 25.2 & Homotetramer & $213 Y$ & n.d. & O75715 \\
\hline GPX-6 & $\begin{array}{l}\text { Selenocysteine in } \\
\text { Humans. Cysteine } \\
\text { in rodents }\end{array}$ & 24.9 & Homotetramer & n.d. & n.d. & P59796 \\
\hline GPX-7 & Cysteine & 20.9 & Monomer & 2P31 & n.d. & Q96SL4 \\
\hline GPX-8 & Cysteine & 23.8 & Monomer & $3 C Y N$ & n.d. & Q8TED1 \\
\hline
\end{tabular}

Comparison of structural features among the Glutathione Peroxidase family. RCSP Protein Data Bank (PDB) codes. Molecular weight values are reported from the Uniprot database (UniProthttps://www.uniprot.org). The molecular weight of a particular crystal structure may differ depending on the method used for crystallization. Abbreviations. kDa, Kilodalton; n.d., not discovered. 
The most unique feature of the mammalian GPX family is that many of them, apart from GPX-5, GPX-7, GPX-8, and GPX-6 in rodents, are selenoproteins [13]. Selenoproteins are rare proteins with strong antioxidant activity containing the 21st amino acid, selenocysteine. Selenocysteine ( $\mathrm{Sec}$ ), differs from cysteine (Cys) by a single atom, selenium replacing sulfur (Figure 1). Selenium incorporation into Sec is a highly complex process, owing to the complex genetic machinery required for both the synthesis of Sec-specific tRNA, and the co-translational use of the codon "UGA", which also functions as the stop codon[14,15]. The biosynthesis of Sec is significantly more complicated than the other proteinogenic amino acids, including Cys [16]. Although Se incorporation is challenging, Se is essential for life and required for the proper enzymatic function of selenoproteins such as glutathione peroxidases (GPX) and thioredoxin reductases (TrxR) [17]. This raises an important question - what is the advantage of opting to use selenium when sulfur is structurally similar and requires fewer complex mechanisms to be utilized? This answer is not clear, although it may be explained by the difference in kinetic and thermodynamic properties of selenols compared to thiols [18,19]. A detailed chemical comparison between sulfur and selenium was recently examined, highlighting that the greatest difference between the two atoms occurs in their redox properties [20]. Se is both a good nucleophile and a good electrophile, which gives the atom the special ability to seamlessly cycle between reduced and oxidized states without becoming permanently oxidized. Past studies by Maiorino et al. showed that the replacement of sulfur with selenium in cysteine-containing enzymes leads to a substantially enhanced catalytic activity [21]. Accordingly, a recent study by Ingold et al. suggested that thiol-based catalysis is prone to overoxidation, whereas selenol-based catalysis is resistant to overoxidation [22]. Overoxidation of the selenoprotein would inactivate that protein, and thus prevent it from carrying out its oxidative functions. The superior redox properties of Se are a likely explanation for why Se is essential to selenoproteins despite its incorporation challenges.

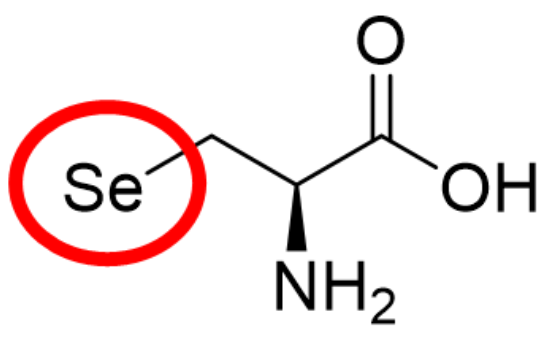

Selenocysteine

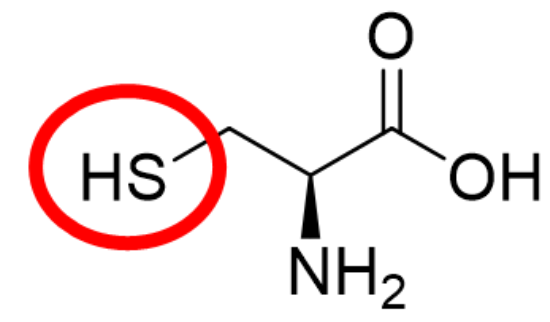

Cysteine

Figure 1. Chemical structure of selenocysteine and cysteine. The two compounds differ by a single atom, a selenium atom in selenocysteine and a sulfur atom in cysteine. The presence of selenium improves the redox properties of a given protein (e.g., GPX family, thioredoxin reductase, selenoprotein $\mathrm{P}$ ).

A trace element of Se was first discovered in 1817 by the Swedish chemist Jons Jacob Berzelius. Se is today appreciated as one of the most required micronutrients for humans. Se has a vast number of promising roles in the human body, including antioxidant, antiinflammatory, and anti-carcinogenic effects that are linked to its incorporation in selenoproteins [23,24]. The role of Se as a potential therapeutic target for cancer was recently reviewed [25]. Humans consume selenium through vegetables, meats, and dietary supplements. Se deficiency has been linked with adverse health conditions such as cardiovascular disease, infertility, myodegenerative diseases, and cognitive decline [26,27]. Se levels are highest in the kidney, followed by the liver, spleen, pancreas, heart, and brain. When Se uptake is deficient, these ranking changes depending on the priority order of these different organs for access to Se [28]. Interestingly, the brain retains Se longer than 
the other organs, highlighting the potential importance of Se in the central nervous system [29]. Indeed, a recent study identified the role of selenoproteins in brain function and implicated Se as a potential target in Alzheimer's disease [30].

The GPX family is the major selenoprotein in the human body, but others such as the thioredoxin reductase family and the selenoprotein $P$ family also exist. While the role of selenoproteins as an antioxidant is well established and biologically relevant, recent studies have shown that selenoproteins also have diverse roles unrelated to maintaining oxidative homeostasis [23]. Likewise, Selenium containing GPX enzymes (SecGPXs) can have diverse functions in the human body that extend beyond their principal role as an oxidoreductase. There are few human GPX enzymes that lack selenoprotein character and instead have a cysteine residue in their catalytic center rather than a selenocysteine residue. These enzymes are GPX5, GPX7, and GPX8. According to phylogeny studies, more than 700 Cys containing GPX-homologous sequences have been identified across many living organisms, indicating that only a small minority of GPXs are selenoproteins. [8]

\subsection{The Biochemical Structure of Glutathione Peroxidase}

A typical mammalian GPX is characterized by the presence of a conserved catalytic tetrad consisting of glutamine, tryptophan, asparagine, and either a selenocysteine or cysteine residue [31]. (See figure 2 for the amino acid sequence alignment comparing human GPX1-through-GPX8). The redox-active selenium is at a hydrogen-bonding distance from the three other residues located in the active site, which is positioned at the protein surface. Most of the GPx enzymes are homotetramers apart from Gpx4, GPx7, and Gpx8, which are monomers. The monomeric enzymes are distinct in the accessibility and electrostatic environment of the active site [32]. The unique monomer structure is speculated to allow the reduction of more complex lipid peroxides, although this has only been proven for GPX4. All GPX homologs display a tertiary structure conserved in thioredoxins and other oxidoreductase families. This conserved structure contains four $\alpha$-helices that are localized near the protein surface, and seven beta-strands, five of which cluster together forming a central b-sheet [8]. (See figure 3 for the structural representation of GPX4). 


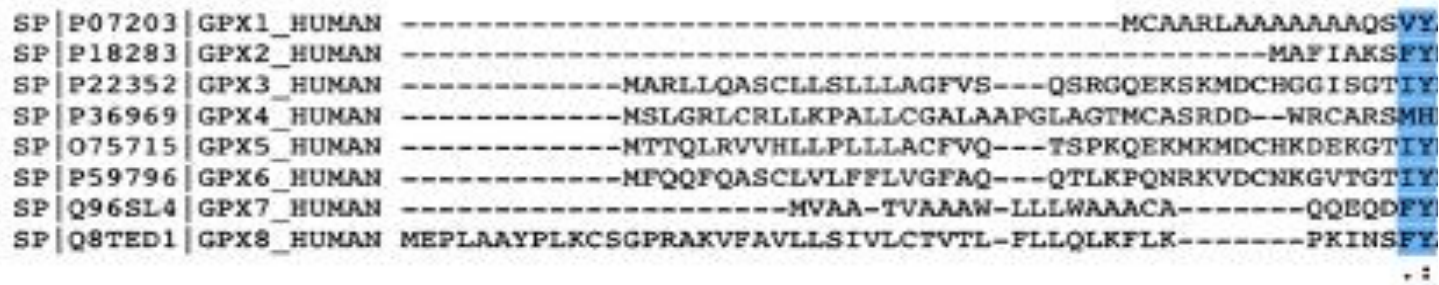

SP|P07203|GPX1_HUMAN RPLAGGEPVSLGSLRGXVLIIEUVASLUGTTVRDYTOMUELQRRLGPRGLVVLEF2 SP|P18283|GPX2_HUMAN ISL-DGEKVDFNTFRGRAVLIEKVASLUGTTIRDFIOLAELOCRF-PRRLVVLGPP SP|P22352 | GPX3 HUNAN LTIDGEEYIPPKOYAGKYVLFVUVASYUGLT-GOYIELWALOEELAPFGLVILGFP SP |P36969|GPX4_HUNAN KDT-DGHMVNLDKYRGFUCIVINVASQUGKTEVNYTQLVDLHARYABCGLRTLAFP SP $1075715 \mid$ GPXS HUNAN IALNKEEYVSPKQYVGKHILPVNVATYCGLT-AOYPELNALOSELKPYGLUVLGFP SP [P59796 | GPX6 HUMAN LTLNGEEYIOFKQPAGKHVLPVWVAAYUGLA-AOYPELMALQEELXWTGVIVLAFP SP $\mid$ Q96SLA | GPX7_HUMAN VNI-RGKLVSLEKYRGSVSLVWRVASECGFTDQHYRALOQLQRDLGPHHFNVLAFP SP |Q8TED1 | GPX8_HUNAN KDA-KGRTVSLEKYKGKVSLVVIVASDCOLTDENYLCLKRLHKEFGPSHFSVLAFP

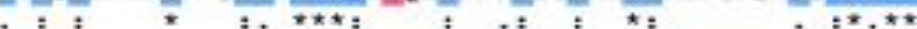

SP|P07203|GPX1 HUMAM GBOENAKKEYTLNSLKYYRPGGGFEPKPMLFEKCEVWGAGAHPLFAFLREALPAPS SP [P18283 |GPX2_HUMAN GHQYNCQNEEILNSLKYVRPGGGYQPTPTLVOKCEVNGONEHPVPAYLKDKLPYPY SP|P22352 |CPX3_HUNAN CKOEPGENSEILPTLKYVRPCGCFVPNPOLFEKCDVNGEKEOKFYTFLKNSCPPTS

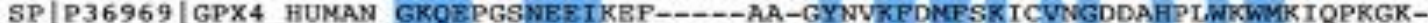
SP 1075715 GPXS_HUNAN GKOEPGDNKEILPGLKYVRPGGGFVPSPOLFEKGDVNGEKEQKVFSFLKHSCPHPS SP |P59796| GPX6_HUMAM GKQRPGTNSEIILGLKYWCPGSGFVPSFOLFEKGDVNGEKEQKVT IPLKNSCPPTS SP [Q96SL4 | GPX7 HUMAM GQQEPDSIKE IESP-----ARRTYSVSPPMPSKIAVTGTGAHPAPKYIAQTS---SP|QBTED 1 | GPX8_HUNAN GESEPRPSKIVESF---.-ARKMYGVTPPIFHKIKIIGSEGEPAFRFLVDSS--.--

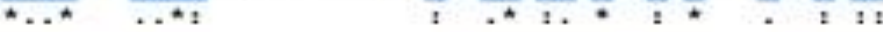

SP|P07203 |GPX1_HUMAM ALMTDPKLITWSPVCRNDVRWAFEKFLVGPDGVPLRRYSRRFOTIDIEPDIEALIS SP|P18283 |GPX2 HUNAN SLMTDPKLIIWSPVRRSDVRWM EKFLIGPEGSPFRRYSRTFPTIWIEPDIKRIIX

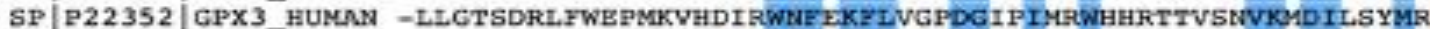

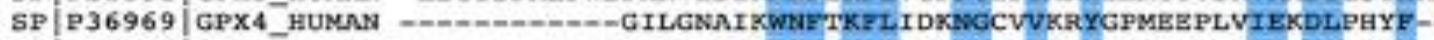
SP $1075715 \mid$ GPXS HUNAN -ILGTFKSISWDPVKVHDIRWRE KKFIVGPDGIPVMRWSHRATVSSVKTDIL.AYLK SP |P59796 [ GPX6 HUMAN -LLGSSSQLFWEPMKVHDIRWNFEKF LVGPDGVPVMHWFHQAPVSTVKSDILEYLK

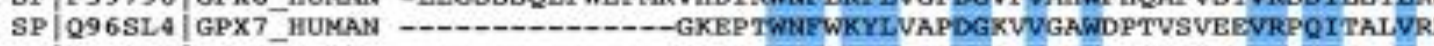

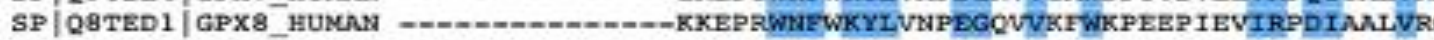

SP|P07203|GPX1 HUMAN CA---- 203

SP|P18283|GPX2_HUMAM -...--

SP |P22352 | GPX3 HUMAM LGVKRK 226

SP $|P 36969|$ GPX4 HUMAN -..--

SP $|075715|$ GPXS HUMAN K----- 221

SP |P59796|GPX6 HUMAN H--.-- 221

SP 1096 SL 4 GPX7 HUMAN LKREDL 187

SP|QBTED1|GPX8_HUMAN KKKEDL 209

Figure 2. Amino acid sequence alignment adapted from Uniprot comparing human GPX1-throughGPX8. Blue highlighted regions emphasize similar sequences. The glutathione peroxidase family has overall low sequence similarity. The pink highlight recognizes the redox-active site (U: Selenocysteine; C: Cysteine).

\subsection{General Mechanism of Glutathione Peroxidase}

All Glutathione Peroxidases (GPXs) display a ping-pong mechanism, a type of non-sequential mechanism [32]. The well-known GPX mechanism involves two steps - an oxidation reaction followed by a reduction reaction [13]. The first step consists of the oxidation of the reduced GPX enzyme hydroperoxide-type compound, while the second step is a series of reductions of the oxidized GPX enzyme by a thiol-containing compound such as the reduced cofactor glutathione (GSH). In the GPX catalytic site and during the initial step, the selenocysteine or cysteine gets oxidized to selenic or cysteinic acids. At the same time, the toxic hydroperoxide gets converted into its respective benign alcohol. 
This step is believed to occur without the standard formation of an enzyme-substrate complex, which allows an incredibly rapid reduction of the substrate. Indeed, the rate constant for the oxidation phase is near $10^{8} \mathrm{M}^{-1} \mathrm{~S}^{-1}$, which is among the fastest ever determined for biomolecular enzymatic reactions [8]. The reduction phase involves two subsequent steps, the first producing a glutathionylated intermediate GPX enzyme where the oxidized GPX reacts with the first equivalent of GSH. In the next step, a second equivalent of GSH reacts with the glutathionylated intermediate to form the stable product GSSG, and this allows the release of the reduced selenium or cystine for the next catalytic cycle (see figure 4 for an example of GPX4 oxidoreductase mechanism).

\subsection{Substrate Specificity}

Glutathione peroxidases (GPXs) have a diverse range of oxidizing substrates. Most GPXs reduce small organic hydroperoxides but are unable to reduce complex hydroperoxides such as lipid hydroperoxides or cholesterol. The one exception to this is GPX4, which is unique in being the only GPX enzyme capable of reducing large and complex lipid hydroperoxides and cholesterols, even when they are embedded in the biological membrane [33]. Glutathione (GSH) is the most preferred co-factor reducing substrate in mammalian GPX enzymes, although GPX4 has the unique ability to utilize other protein thiols in addition to GSH [34].

\subsection{Role of Oxidative Stress in Biology}

The GPX's primary role as an oxidoreductase is significant as it helps to prevent oxidative stress and oxidative damage, which are prominent biomarkers for human disease [35]. In recent years oxidative stress has been recognized for its role in a number of disorders including Alzheimer's and Parkinson's disease [36,37], cancer, [38,39], diabetes, [40] and cardiovascular diseases [41,42]. Oxidative stress is characterized by an imbalance between prooxidant species that promote oxidation, and antioxidant species that inhibit this oxidation. Prooxidants are oxidizing agents such as reactive oxygen species (ROS) and reactive nitrogen species (RNS). Meanwhile, antioxidants can be macromolecule enzymes (e.g., GPX and transferrin) and small molecules (e.g., vitamins E; C; A) substances that prevent or reduce the oxidation of polyunsaturated fatty acids that may be exposed to oxidation.

\subsection{Glutathione Peroxidase in Health and Diseases}

An intensive review comparing the history, biochemistry, genetics, and biomedical relevance of each GPX enzyme was recently published [13]. Briefly, the GPX 1-8 genes are mapped to chromosomes 3, 14, 5, 19, 6, 6, 1, and 5, respectively. While all GPXs are generally involved in the detoxification of prooxidants, each GPX has distinct roles in biology [13]. GPX1 is most known for maintaining peroxide homeostasis in the insulin signaling pathway [43], along with its complex role in cancer as an antiapoptotic enzyme [44]. GPX2 plays a unique role in carcinogenesis [45-47]. GPX3 acts as a tumor suppressor [48,49]. GPX4 is involved in the regulation of cell death including ferroptosis [50], and together with GPX5, in male fertility [51,52].The functions of GPX6 are less well known, but recently it has been implicated as modulator of Huntington's disease [13,53]. GPX7 and GPX8 are speculated to be involved in protein folding [54,55] (See table 2 for a comparison of the biological properties of each enzyme). Although the functions of GPX1 - GPX8 extend much beyond their oxidative roles, GPX4 is the only GPX that when knocked out (GPX4KO) is lethal. This suggests that GPX4 exhibits specific biochemical and molecular functions that are essential for human health and diseases, thereby making the enzyme an attractive target for novel therapeutic opportunities.

\section{Glutathione Peroxidase 4 in Biochemistry and Molecular Biology}




\subsection{The Origins of Glutathione Peroxidase 4}

GPX4, initially called phospholipid hydroperoxide glutathione peroxidase (PHGPX), was first purified in 1982 by Ursini et. Al [56]. Ursini and colleagues were studying the protein contents of the cell sap, a fluid found in the living cell of the small cavities of vacuoles, from pig liver when they found glutathione peroxidase that had a unique ability to protect liposomes and biological membranes from oxidative degradation. Indeed, the ability to reduce complex hydroperoxides including the phospholipids embedded in biological membranes remains a distinctive and crucial feature of this enzyme. PHGPX was later found to contain selenocysteine and to have a unique monomer structure [57]. In 1991, primary structure studies revealed that PHGPX was a new selenoprotein distinct but related to GPX-1, allowing PHGPX to be considered a new member of the glutathione peroxidase family [58]. Today, PDHGPX is known as GPX4 and is recognized as a key mediator of a variety of human diseases including certain cancers, neurodegenerative disorders, and rare genetic disorders [59]. There are several key features that make GPX4 unique from the other enzymes in the GPX family including its monomeric structure, its unique ability to reduce complex lipid hydroperoxides specifically, its broader substrate specificity, its vital role in early mouse development, and its involvement in an impressive variety of biological processes [60]. In addition to the small hydroperoxides that are common substrates for all GPX enzymes, only GPX4 can reduce complex phospholipid hydroperoxides specifically, even those embedded in the biological membrane, to their corresponding benign alcohols. This function is of particular therapeutic interest as it suggests GPX4's role in maintaining the integrity of biological membranes. In addition, GPX4 has a broader substrate specificity than other GPX enzymes as it is not limited to only glutathione as a reductant. Rather, GPX4 has the unique ability to get reduced by thiol-containing proteins as well [61,62] which increases its biological relevance.

\subsection{Biological Relevance of Glutathione Peroxidase 4}

GPX4 represents an intriguing specific target for new pharmacological treatments, precision therapies, and other therapeutics. GPX4 has emerged as a hotspot in biomedical research following its recognition as a chief regulator of an emerging form of regulated cell death called ferroptosis [50]. Ferroptosis is relevant to a multitude of diseases as discussed later in this review. In a recent paper, GPX4 was implicated in a rare genetic disorder called Sedaghatian-type Spondyloepiphyseal Dysplasia (SSMD) [59]. The CureGPX4 organization was recently developed to identify and develop treatments for GPX4 related diseases, such as SSMD. GPX4 is recognized as essential for proper embryo development, as GPX4 knockout mice die in utero [63,64]. The therapeutic basis of GPX4 in cancer, [65,66], neurodegenerative disorders [67-69], and male infertility [51,70] have been investigated.

\subsection{Structure and Genetics of Glutathione Peroxidase 4}

The human GPX4 gene is located on chromosome 19 at band 19p13.3. The mammalian GPX4 gene contains seven exons and six introns expressed in three different splice variants ((i) the cytosolic isoform (c-GPX4), (ii) the mitochondrial isoform (m-GPX4), and (iii) the nuclear isoform (n-GPX4)) [8]. GPX4 transcription is regulated by stimulating proteins 1 and 3 (SP1/3) and nuclear factor Y (NF-Y). nGPX4 and mGPX4 are involved in sperm cell maturation among other diverse functions distinct from the lipid hydroperoxide activity that primarily defines cGPX4. The Uniprot data bank characterizes GPX4 as a 197 residue-containing protein with a molecular mass of $22 \mathrm{kDa}$. GPX4 presents with a typical thioredoxin motif containing four $\alpha$-helices that are localized near the protein surface, and seven b-strands, five of which cluster together forming a central b-sheet. 
(See figure 3 for a crystal structure representation of GPX4 adapted from the PDB $(6 \mathrm{ELW}))[71]$.

(A)

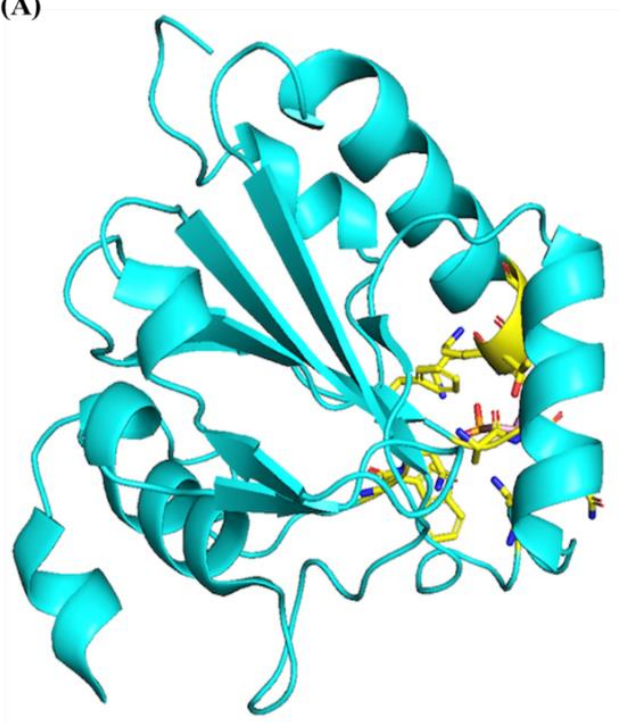

(B)

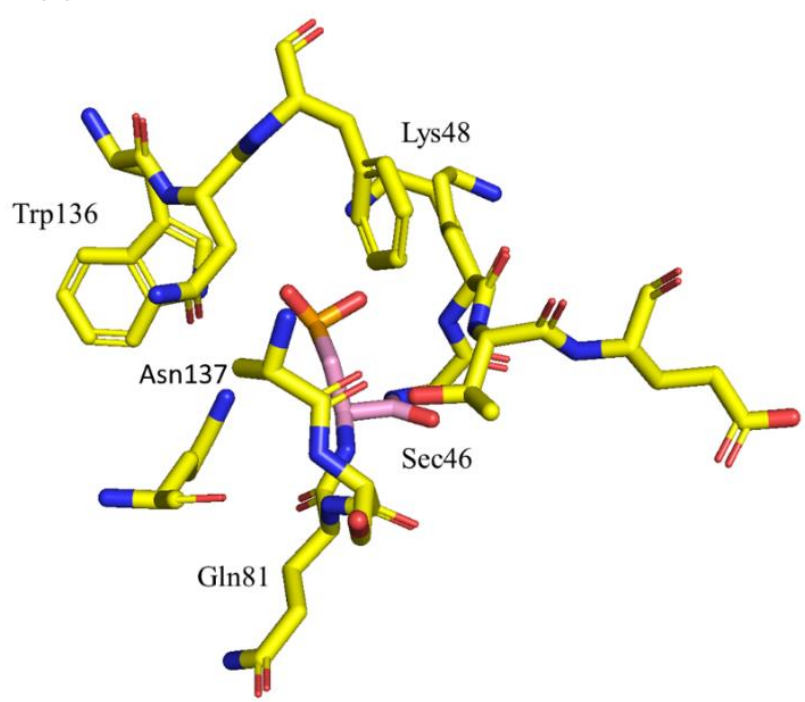

Figure 3. Crystal Structure of the apo selenocysteine-containing human GPX4 protein adapted from the protein data bank (PBD code: 6ELW, 192 residues, $21.91 \mathrm{kDa}$ ). Structure was originally reported by Borchert et al [71]. (A) Shows the full crystal structure of GPX4 (PDB entry 6ELW). (B) Shows the active site residues of the GPX4. Selenocysteine at position 46 in the active site (highlighted in pink color). Surrounding active site residues (highlighted in yellow color).

GPX4 shares the conserved catalytically active tetrad observed in other SecGPXs containing selenocysteine (Sec46), glutamine (Gln81), tryptophan (Trp136) and asparagine (Asn137). Gln81 and Trp136 function to stabilize Sec46, especially the selenium redox intermediates (Se-, SeO-) through a network of hydrogen bonds. Asn137's primary function is in the catalytic mechanism [72]. Mutations of any of these residues reduces GPX4 activity. Mutations of the selenocysteine to cysteine reduces GPX4 activity by 90\%, highlighting the importance of the selenoprotein characteristic [33]. The monomeric GPX4 structure is missing an internal stretch of 20 amino acids that are conserved in the tetrameric GPX enzymes. These 20 residues code for a solvent-exposed loop surrounding the active site, and this loop may prevent complex substrates from accessing the active site. The lack of this loop in GPX4 is speculated to give GPX4 its unique ability to reduce large and complex substrates such as phospholipid peroxide. Crystal structures of cGPX4 have traditionally been solved using Sec46Cys mutants, rather than the native protein, due to the inherent challenge of expressing selenoprotein-containing proteins in sufficient quantities [73]. Human GPX4 Sec46Cys crystal structures are well-studied [74] and very similar to crystal and solution studies of mouse Sec46Cys mutants that have recently been solved [31]. The solving of a true, selenium-containing wild-type human protein would improve the understanding of GPX4 functional interactions and may facilitate the pharmacological development of GPX4-targeting compounds. The first crystallization and structural determination of a true wild-type SecGPX4 protein was solved recently by Moosmayer et al. [75]. This feat was accomplished using a novel approach first described in [75]. The wildtype selenium-containing crystal structure is structurally similar to previously reported mutant GPX4 structures as compared in a previous study [71]. The biggest structural difference between the Sec46Cys and Sec46 GPX4 variants was at the active site. For the Sec-containing enzyme, the hydrogen bond distance between the Sec46 and the Gln81 of the catalytic site is much shorter, at $3.2 \AA$. In a recent study by Labreque et. al, the first NMR assignments of GPX4 were presented [32]. Together, this work provides a starting point for improving the understanding of the structural drivers of GPX4 interactions with its targets. 


\subsection{Enzymology and Kinetics of Glutathione Peroxidase 4 and GSH}

The mechanism of GPX4 is identical to the other SecGPXs described earlier in this report (Figure 4). GPX4 displays a ping-pong mechanism involving the redox shuttling of the selenocysteine active site between an oxidized and a reduced state. GPX4 does not follow Michaelis-Menten kinetics, likely because the rate-limiting step during this mechanism is not the decay of the GPX-substrate complex, but rather the initial binding of the peroxide to the GPX active site. During the first phase, GPX4 catalyzes the reduction of the toxic lipid peroxides to the non-toxic lipid alcohols through the oxidation of the active site selenol (Se-H) to selenenic acid (Se-OH) (Figure 4). During the second phase, a reducing substrate such as GSH is used to reduce the selenenic acid back to the active selenol and close its catalytic cycle and allow the oxidation/reduction process to be repeated. The catalytic process is executed in two steps, starting with the reaction of GSH forming a selenium-glutathione intermediate. Next, the selenenic acid is reduced back to the selenol together with the release of glutathione disulfide (GS-SG) (Figure 4). Interestingly, a recent crystal structure showed the presence of a seleninic acid in the GPX4 active site [71]. This may suggest a two-cycle mechanistic model, where the shuttling of selenium between selenol (R-Se-H) and selenenic acid (R-SeO-H) may be extended by shuttling selenenic acid (R-SeO-H) to seleninic acid (R-SeOO-H), although this has not been experimentally verified. It may be possible that depending on cellular conditions, GPX4 may utilize either the "low-oxidation" (R-SeO-) or the "high-oxidation" (R-SeOO) cycle. Central to the enzymatic mechanism of GPX4 is the thiol-containing tripeptide, Glutathione. Although GPX4 is unique from the other GPX enzymes in that it is not limited to GSH and may use other thiol-containing proteins as reductants as well. However, GSH is the most abundant in cells. In addition, the reducing form of GSH is implicated as an antioxidant marker for several human diseases [76-78]. In recent years it has become recognized as a key regulator, alongside GPX4, in an emerging regulated cell death pathway called ferroptosis [79]. Ferroptosis is a recently reported non-apoptotic programmed cell death mediated by the GSH /GPX4 cellular pathway. The role of GSH as the most abundant antioxidants synthesized in cells is well studied, established by their role in removing reactive oxygen species [80]. Glutathione is made up of L-glutamate, cystine, and glycine residues. Its synthesis is catalyzed first by glutamate cystine ligase (GCL), which couples to ATP hydrolysis to form an amide bond between the carboxyl group of glutamate and the amino group of cysteine. Glutathione synthase then adds glycine to the dipeptide to create GSH, a step that is also coupled with ATP hydrolysis. Glutathione exists in the reduced form (GSH) or oxidized glutathione disulfide form (GGSG). GSH exhibits a strong electron-donating character, owing to its sulfhydryl group on the cysteinyl position. As GSH loses electrons to become oxidized, two GSH molecules dimerize through a disulfide bridge to form GSSG [78]. Importantly, this dimerization is reversible through a reduction reaction. GPX4 uses glutathione as a cofactor to reduce peroxides to their corresponding alcohols, which is important in blocking the formation of reactive oxygen species and subsequently preventing oxidative damage. The GPX4, GSH, and GSSG team is the main antioxidant system that protects living organisms from oxidative stress and oxidative damage. 


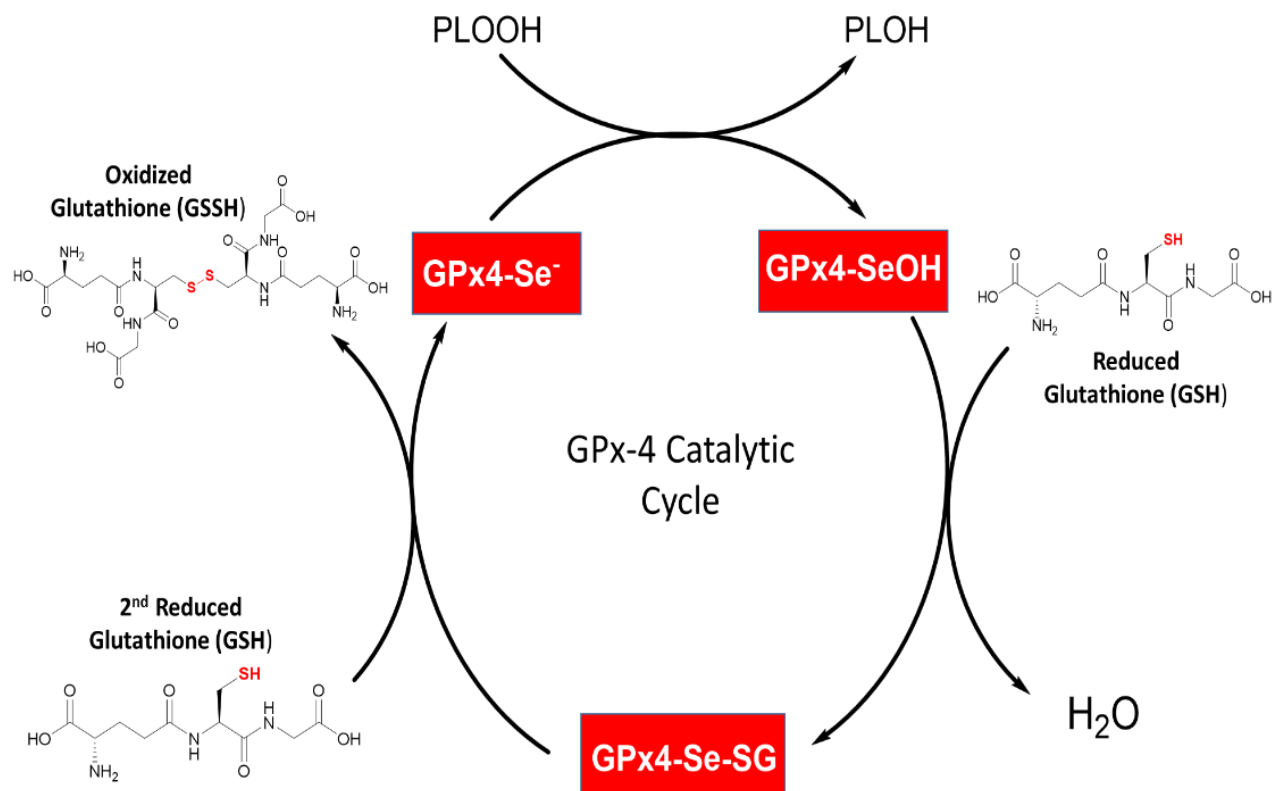

Figure 4. GPX4 catalytic cycle representation. GPX4 selenol (GPX4-SeH) gets oxidized into selenic acid (GPX4-SeOH). This oxidation powers the reduction of toxic lipid hydroperoxides into their respective alcohol. The selenic acid is reduced back to its active form selenol using two equivalents of GSH. The first equivalent of GSH reacts with selenic acid to form a selenium-glutathione intermediate and generate water. While the second GSH equivalent reacts to reduce the selenium-glutathione intermediate into a selenol together with the release of glutathione disulfide (GSSG).

\subsection{Synthesis, Degradation, and Regulation of Glutathione Peroxidase 4}

The protein synthesis and degradation of GPX4 are tightly regulated by a network of complex mechanisms. The presence of selenium is important in the synthesis of an enzymatically active GPX4, especially in relation to its role as a ferroptosis-mediator [22]. Isopentyl pyrophosphate (IPP) produced by the mevalonate pathway also favors GPX4 protein synthesis. Heat shock protein family A member 5 (HSPA5, also known as BIP) is a molecular chaperone which directly binds to GPX4 in order to prevent its degradation [81]. HSPA5 is especially interesting as its functioning may be implicated in cancer cell resistance to ferroptosis. Heat shock protein 90 (HSP90) mediates GPX4 degradation, which has an opposite effect compared to HSPA5, as it facilitates ferroptosis

\section{Glutathione Peroxidase 4 as a Chief Regulator of Ferroptosis}

\subsection{Overview of Ferroptosis}

Regulated cell death (RCD) is a highly controlled modality involving tightly structured signaling cascades and effector mechanisms. Proper RCD function is necessary for the development and maintenance of tissue homeostasis and as a mechanism for eliminating damaged cells. RCD is particularly relevant in neurodegenerative diseases, cancers, and the development of multicellular organisms [82]. Apoptosis was the first and most well-known RCD mechanism characterized in 1972 by John Kerr et al. [83]. The development of therapeutics for cancers and other diseases characterized by abnormalities in RCD requires a comprehensive understanding of the multitude of cell death mechanisms and their subtypes [84]. Cell death mechanisms in mammalian cells have been traditionally classified as apoptotic, necroptotic, or autophagic. In recent years, however, several novel forms of cell death have been discovered and it is thought that many more may exist. A form of regulated cell death named "ferroptosis" has become a hotspot in biomedical research as it plays a critical regulatory role in an impressive variety of human diseases. Ferroptosis was recently implicated as a mechanism of neurodegeneration in Alzheimer's Disease [69], and as a mechanism for neuroinflammation in Parkinson's 
Disease $[85,86]$. Ferroptosis is seen as a novel therapeutic for several neurodegenerative disorders including Alzheimer's, Parkinson's and Huntington's disease [87,88]. Studies involving ferroptosis in neurodegenerative disorders are generally aiming to inhibit ferroptosis cell death, however, inducing ferroptosis is also a promising therapy for disorders such as cancers. Indeed, ferroptosis is implicated in a vast number of cancers including prostate [89] and lung cancers [90,91]. The therapeutic potential of ferroptosis in human disease is extensive and its implication in a wide range of disorders is accelerating. [42,92,93]. Early research on ferroptosis-characteristic cell death is dated back to the 1950s and 1960s, led by Harry Eagle who demonstrated that cysteine depletion reduced glutathione and led to cell death, whereas cysteine synthesis protected cell death by restoring glutathione [94-96]. Additionally, an antioxidant named a-tocopherol (a type of vitamin E) rescued cell death independent of glutathione [97]. A group led by Joseph Coyle established glutamate-induced cell death dependent on the inhibition of cystine transport, which was later named oxytosis in 2001, and considered today as a subtype of ferroptosis. [98,98,99]. In 2012, the term "Ferroptosis" was named and characterized as a distinct form of regulated cell death driven by the iron-dependent accumulation of lethal lipid reactive oxygen species by Dixon, et al. [100]. Dixon and colleagues discovered that ferroptotic cell death is morphologically biochemically, and genetically distinct from other forms of cell death. The features of ferroptotic cell death, especially in comparison to other forms of cell death, were described comprehensively in a recent paper [101]. Briefly, at a morphological level ferroptosis-induced cells have reduced mitochondrial volume, increased bilayer membrane density, and reduction of mitochondrial cristae. Biochemically, cells present with depletion of intracellular glutathione and subsequent decreased activity of GPX4.This foreshadows the vital role GPX4 plays in the regulation of ferroptotic cell death. The current understanding of the genetic basis of ferroptosis is incomplete and may be disease-state specific [102,103]. Broadly, at the genetic level ferroptosis is likely to involve genetic changes in iron homeostasis and lipid peroxidation metabolism.

\subsection{Molecular Mechanisms of Ferroptosis}

Ferroptosis is driven by lipid peroxidation and is regulated at multiple levels. Generally, it is characterized by cells accumulating lipid peroxides and failing to utilize the internal defense systems that should eliminate these lipid peroxides. This causes peroxide accumulation to lethal levels which will damage the phospholipids that make up the cell membrane and ultimately cause cell death. There are three main regulatory levels of ferroptosis: (1) Xc/GSH/GPX4, (2) NAD(P)H/FSP1/CoQ10 and (3) GCH1/BH4/DHFR. The system $\mathrm{Xc}_{\mathrm{c}} \mathrm{GSH} / \mathrm{GPX} 4$ pathway was the first discovered and today is recognized as the centerpiece of the ferroptosis mechanism (Figure 5) [50,63]. 


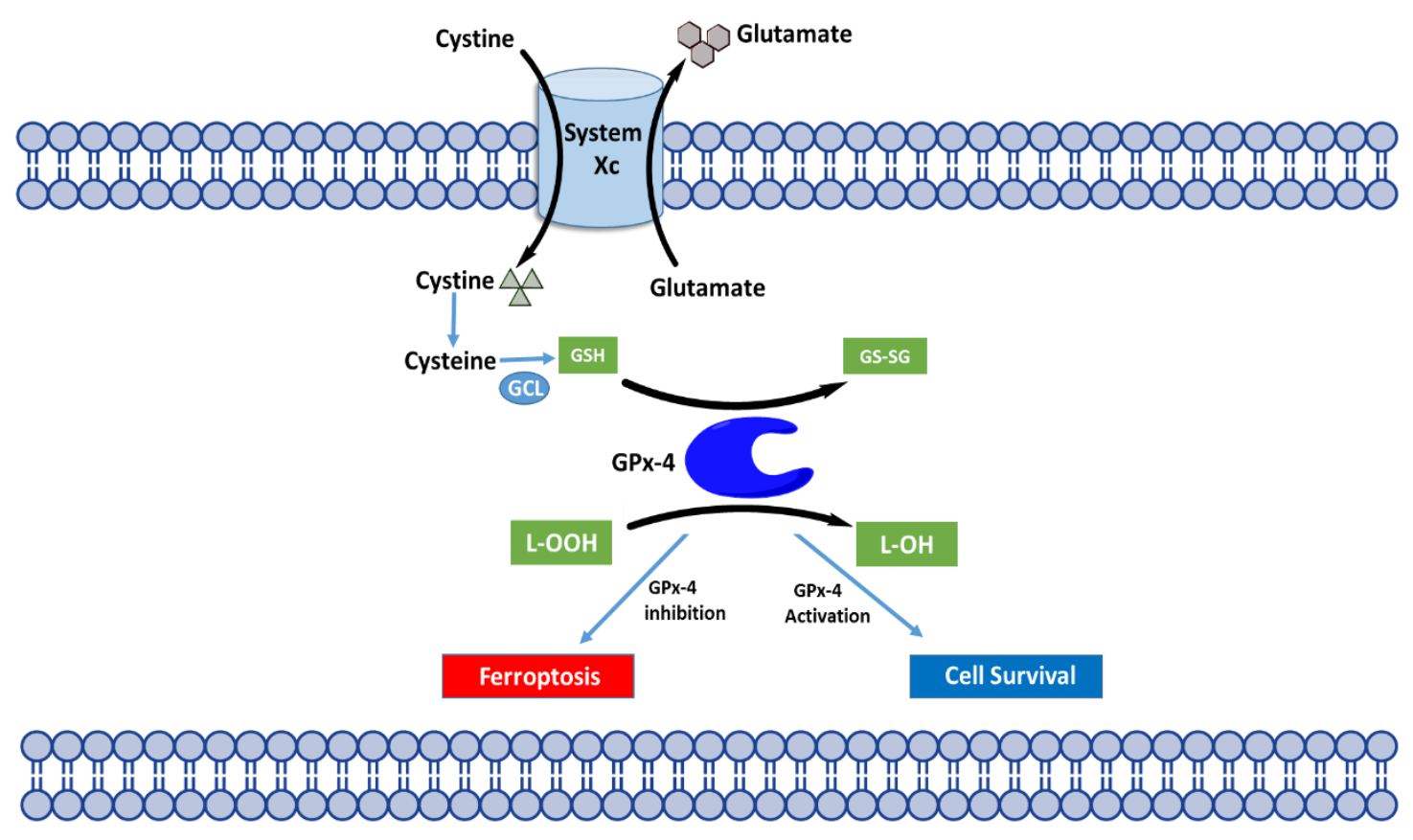

Figure 5. The ferroptotic induced peroxidation of phospholipids is mediated by the cyst(e)ine/GSH/GPX4 regulatory pathway. The system $X_{c}$ antiporter mediates the exchange of extracellular cystine with intracellular glutamate. When cystine is internalized, it gets reduced to cysteine which is one of the precursors for the biosynthesis of GSH. GPX4 utilizes GSH as a cofactor for the reduction of toxic lipid peroxides into the respective alcohols. Depletion of either GSH or GPX4 will cause an increase of lipid peroxides that will damage the cell membrane, and lead to ferroptotic cell death - a form of cell death implicated in a wide variety of human diseases.

A characteristic feature of ferroptosis is the accumulation of phospholipid hydroperoxides in the presence of catalytically active iron. This process is naturally inhibited by the system Xc/GSH/GPX4 regulatory pathway. The most upstream component of this pathway is a heterometric antiporter known as system $X_{c}$, which is widely distributed in biological membranes. The antiporter mediates the exchange of extracellular cystine (the oxidized form of cysteine) and intracellular glutamate with a stoichiometry of 1:1 [104]. This exchange is essential for the biosynthesis of GSH. When cystine is internalized, it gets rapidly reduced to cysteine by GSH (and/or thioredoxin reductase 1), and that reduced cysteine is then used for GSH biosynthesis. GSH as mentioned earlier is the most important antioxidant in cells, and GSH also functions as a cofactor for GPX4-mediated antioxidant defense. [105]. System $X_{c}$ is made up of two central components, solute carrier family 3 member 2 (SLC3A2) and solute carrier family 7 member 11 (SLC7A11). A number of tumor suppressor genes, including p53 [106] and BRCA-1associated 1 (BAP1) [107], suppress SLCA11 and overall system Xc activity. Disturbing system Xc (e.g., glutamate, erastin, sulfasalazine and sorafenib), depleting GSH (e.g. buthionine sulfoximine) or inhibiting GPX4 (e.g. RSL3, ML162, Fin56). In addition to the Xc/GSH/GPX4 pathway, 2 additional pathways are recognized as major pathways in the ferroptosis system; the $\mathrm{NAD}(\mathrm{P}) \mathrm{H} / \mathrm{FSP} 1 / \mathrm{CoQ} 10$ and the GCH1/BH4/DHFR systems. The details of these pathways have been described comprehensively in a recent review [108]. An important, yet somewhat controversial feature of ferroptosis is the understanding of how iron is involved [93]. The current understanding based on studies from several groups is that hydroperoxide-generating enzymes called lipoxygenases (LOXs) can initiate ferroptosis by generating lipid peroxides. Then, liable iron (iron not bound to enzymes) propagates these lipid peroxides and leads to the chain reaction of lipid peroxidation $[109,110]$. It is also believed that other iron-dependent enzymes may contribute to lipid peroxidation under specific circumstances 


\subsection{Regulation of Ferroptosis through GPX4}

GPX4 was first recognized in 2014 as a key regulator of ferroptotic cell death by Yang et. al. [50]. Among the three known GPX4 isoforms (ie. mitochondrial, cytosolic, and nuclear), only the cytosolic isoform (c-GPX4) is required for ferroptosis prevention. The unique function of GPX4 to reduce complex hydroperoxides including phospholipid and cholesterol hydroperoxides, protects biological membranes from the lipid peroxidation chain reaction that otherwise would lead to ferroptosis cell death. GPX4 is seen today in biomedicine as a popular genetic and pharmaceutical target for therapies looking to induce or suppress ferroptosis cell death. [111]. As mentioned prior, oxidation of carbon molecules in the mitochondria during cellular respiration is essential for generating energy for the cell in the form of ATP, but it also gives rise to reactive oxygen species. In addition to the mitochondria, ROS may also be generated from lipid metabolism enzymes such as lipoxygenases. The accumulation of ROS can lead to the oxidation of the phospholipids embedded in the membrane, leading to lipid peroxidation and subsequent cell death. GPX4 functions as a mediator of this process, as it converts lipid hydroperoxides $(\mathrm{R}-\mathrm{OOH})$ to lipid alcohols $(\mathrm{R}-\mathrm{OH})$ using reduced $\mathrm{GSH}$ as a cofactor. This prevents the accumulation of ROS and rescues cell membranes from damage. GPX4 is a selenoprotein, thus selenium availability impacts a cell's sensitivity to ferroptosis. Indeed, in studies delivering selenium to cells or animals it was found to suppress ferroptosis likely because it improves the oxidative efficacy of GPX4. Conditions that decrease the GPX4 levels or activity have an immediate impact on cell survival and health. GPX4null mice undergo embryonic lethality, whereas conditional GPX4-mutant mice result in ferroptosis, neurodegeneration [112], loss of antiviral immunity [113], infertility, and ischemia-reperfusion injury in the kidney and liver [114]

\subsection{Modulation of GPX4 to Probe Ferroptosis}

Small-molecule drug discovery is an exciting process pharmaceutical researchers use as a tool for interrogating and perturbing biological systems $\quad[115,116]$. Small-molecule drugs are organic compounds that have a low molecular weight and could target regulatory proteins as a method for probing biologically relevant molecular pathways such as ferroptosis [117]. It is well established that GPX4 is an attractive specific target for new pharmacological therapeutics aiming at activating cell death in cancer or inhibiting cell death in degenerative diseases. Viswanathan, et al, made the striking observation recently that cancer cells in a therapy-induced, drug-resistance state display high levels of polyunsaturated lipids and an acquired dependency on GPX4 [118]. Accordingly, increasing evidence encourages the rational combination of GPX4 inhibitors and current chemotherapies as a dual therapy in a diverse range of cancer types [65,119].

Although there is significant therapeutic benefit to pharmaceutically targeting GPX4, the unique structural features of the protein make it challenging for the development of small-molecule inducers and inhibitors. GPX4 lacks a drug-like binding pocket, and it relies on the nucleophilic selenocysteine residue for proper enzymatic activity. These features may mean that covalent inhibitors are required for inhibition of cellular GPX4, which often have poor selectivity and pharmacokinetic properties. Ferroptosis modulators can be generally classified into three categories: (1) system xc inhibitors, (2) GPX4 inhibitors, (3) compounds that inhibit GPX4 activity via GSH depletion. The first chemical inducer of ferroptosis, identified from a diverse chemical library, was a small molecule named Erastin [120]. Erastin functions to induce ferroptosis through the inhibition of system xc. This results in depletion of glutathione, which subsequently impairs the antioxidant-ability of GPX4, leading to accumulated lipid peroxidation and ferroptotic cell death [121]. Erastin also binds directly to mitochondrial voltage-dependent anion channels. Similar molecules (including sorafenib, glutamate, and sulfasalazine) mimic this indirect GPX4 impairment through the inhibition of system xc have been discovered 
and classified as class 1 inducers (Table 4). Compounds that directly target GPX4 and are independent of system $\mathrm{xc}$, are also promising probes for therapeutics (Table 3). A recent study by Wei, et al. demonstrated that directly targeting GPX4 is more effective than targeting GPX4 indirectly through the distribution of glutathione [122]. In 2008, a novel small molecule inducer of ferroptosis was identified named RSL3 [123]. RSL3 contains a reactive chloroacetamide moiety that makes it a potent and irreversible GPX4 inhibitor, although its poor solubility and poor absorption, distribution, metabolism, and excretion (ADME) properties limit its effectiveness in in-vivo studies. [50]. Several chloroacetamide-containing inhibitors of GPX4 have been identified to date. In 2016, a ferroptotic inducer termed FIN56 was identified as an inducer that works through a dual mechanism of depleting GPX4 protein and mevalonate-pathway-derived coenzyme Q10 (CoQ10). It has become evident that ferroptosis is a druggable pathway where ferroptosis inducers may be used to kill malignant cells, and ferroptosis inhibitors may be used to prevent cell and tissue loss in degenerative disorders. The full scope of pharmaceutical targets for ferroptosis and GPX4 have been summarized intensively in several recent reviews $[117,119,124]$

Table 3. Direct GPX4 Modulators

\begin{tabular}{|c|c|c|}
\hline Compound & Mode of Action & PubChem CID \\
\hline (1S,3R)-RSL3 & $\begin{array}{l}\text { Covalently and irreversibly inhibits GPX4. RSL3 is } \\
\text { potent but has poor ADME properties. [123] }\end{array}$ & 1750826 \\
\hline DP12--DP19 & $\begin{array}{l}\text { Not well characterized. Exhibits potency and } \\
\text { ferroptosis hallmarks [50] }\end{array}$ & 5728915 \\
\hline Altretamine & GPX4 inhibitor [50] & $\begin{array}{c}2123 \\
26186195\end{array}$ \\
\hline DPI10 \& ML210 & $\begin{array}{l}\text { Nitroisoxazole moiety generates a nitrile oxide } \\
\text { electrophile that may react with GPX4 [117] }\end{array}$ & 15945537 \\
\hline ML162 & $\begin{array}{c}\text { Shares the same chloroacetamide moiety as RSL3 } \\
\text { but is otherwise very structurally different. Likely } \\
\text { to have different off-target effects. [50] }\end{array}$ & 3689413 \\
\hline DPI17 \& DPI18 & $\begin{array}{l}\text { Exhibits potency and ferroptosis hallmarks. Likely } \\
\text { to be a covalent GPX4 inhibitor [50] }\end{array}$ & 932617 \\
\hline JKE-1674, JKE-1716 \& BSC144988 & $\begin{array}{l}\text { Identical function as DPI10. Nitroisozazole moiety } \\
\text { leads to a nitrile oxide electrophilic reaction with } \\
\text { GPX4. [117] }\end{array}$ & 145865941 \\
\hline
\end{tabular}


Withaferin A
Acts as a GPX4 inhibitor likely through its electrophilic groups [117]
265237

Established direct modulators of GPX4.

Table 4. Indirect GPX4 Modulators

\begin{tabular}{|c|c|c|}
\hline Compound & Possible Mode of Action & PubChem CID \\
\hline Erastin & $\begin{array}{l}\text { Directly inhibits system Xc causing depletion } \\
\text { of intracellular GSH, which normally works } \\
\text { alongside GPX4 to suppress phospholipid } \\
\text { hydroperoxide accumulation [120] }\end{array}$ & 11214940 \\
\hline $\begin{array}{c}\text { Erastin Derivatives (Piperazine \& } \\
\text { Imidazole Ketone Erastin) }\end{array}$ & $\begin{array}{c}\text { Same proposed mode of action as Erasin. } \\
\text { These derivatives have improved ADME } \\
\text { properties [50] }\end{array}$ & $\begin{array}{c}72710858 \\
\& 91824786\end{array}$ \\
\hline RSL5 & $\begin{array}{l}\text { Displays similar effects as Erastin and may } \\
\text { have identical mechanisms, but this has not } \\
\text { been experimentally verified [123] }\end{array}$ & 2863472 \\
\hline $\begin{array}{c}\text { Sulfasalazine (FDA-approved } \\
\text { drug) }\end{array}$ & $\begin{array}{c}\text { Inhibits system } \mathrm{Xc}_{\mathrm{c}} \text { which causes GSH } \\
\text { depletion. Low potency and metabolically } \\
\text { unstable in vivo. [117] }\end{array}$ & 5339 \\
\hline Glutamate & $\begin{array}{c}\text { Inhibits system Xc likely by inhibiting one of } \\
\text { its kinase targets. May induce necrotic cell } \\
\text { death at high concentrations [99] }\end{array}$ & 23672308 \\
\hline Diaryl-isoxazole & $\begin{array}{l}\text { Non-competitive System Xc-inhibitor } \\
\qquad[117,124]\end{array}$ & n.a \\
\hline Engineered human cyst(e)inase & Systemic Depletion of Cysteine $[117,124]$ & n.a \\
\hline Tac-beclin1 & System Xc-inhibitor $[117,124]$ & n.a \\
\hline $\begin{array}{c}\text { Lanperisone (FDA-approved } \\
\text { drug) }\end{array}$ & $\begin{array}{l}\text { Inhibits cystine uptake, Causes GSH } \\
\text { depletion }[117,124]\end{array}$ & 198707 \\
\hline Sorafenib & $\begin{array}{c}\text { Inhibits system Xc, Causes GSH depletion. } \\
\text { Also activates NRF2 against ferroptosis } \\
{[121,50]}\end{array}$ & 216239 \\
\hline
\end{tabular}




\begin{tabular}{|l|c|c|}
\hline FINO2 and FIN56 & $\begin{array}{c}\text { Does not directly target GPX4, system Xc, or } \\
\text { CoQ10. Rather, it oxidizes iron which leads to } \\
\text { the subsequent inactivation of GPX4 activity. } \\
{[124]}\end{array}$ & \\
\hline
\end{tabular}

Established indirect modulators of GPX4. Abbreviations. NRFT: The nuclear factor erythroid 2-related factor 2.

\section{Conclusions and Perspectives}

The selenoprotein glutathione peroxidase 4 is quickly emerging as an intriguing therapeutic target, owing to its essential role in protecting cellular membranes from oxidative damage. GPX4's primary function is in preventing toxic lipid hydroperoxide accumulation by converting hydroperoxides into their respective non-toxic alcohol. Crucially, GPX4 is recognized as the chief regulator of ferroptosis one of the recently identified regulated cell death mechanism. The body of research on GPX4 is large, and accelerating, as researchers continue to uncover how GPX4 is implicated in human diseases and how inactivation of GPX4 leads to lipid peroxidation-induced ferroptosis. There remains much to learn about the roles, regulation, and therapeutic intervention of GPX4. A challenge in the coming era of GPX4 research will be improving the structural understanding of the wild-type GPX4 protein. Due to the challenges of solving the crystal structure of a selenium-containing protein, there are limited wild-type crystal structures for human GPX4 available. The continued development of a true selenium-containing enzyme may facilitate the pharmaceutical development of GPX4 targeting compounds. In the absence of new therapeutic interventions, GPX4-mutants will contribute to the pathogenesis of a growing number of diverse human diseases. Increasing understanding of the role and regulation of GPX4 will hopefully encourage clinical advancement in cancer therapy, neurodegenerative disorders, and more.

Author Contributions: : Conceptualization, R.S., K.W.; Writing-Original Draft Preparation, K.W. and R.S.; Writing - Review \& Editing, K.W and R.S.; Visualization, K.W.; Supervision, R.S.; Funding Acquisition, R.S. All authors have read and agreed to the published version of the manuscript.

Funding: This research received no external funding.

Institutional Review Board Statement: Not applicable.

Informed Consent Statement: Not applicable.

Data Availability Statement: Data is contained within the article.

Acknowledgments: The authors thank the: (i) Department of Chemistry and Department Biology at the University of Massachusetts (UMASS), (ii) Lung Cancer Research Foundation, (iii) Institute for Applied Life Sciences/Collaborative Cancer Research Grant at UMASS for financial support.

Conflicts of Interest: The authors declare no conflict of interest.

\section{References}

1. Mills, G.C. Hemoglobin Catabolism. I. Glutathione Peroxidase, an Erythrocyte Enzyme Which Protects Hemoglobin from Oxidative Breakdown. J. Biol. Chem. 1957, 229, 189-197.

2. Christophersen, B.O. Reduction of Linolenic Acid Hydroperoxide by a Glutathione Peroxidase. Biochim. Biophys. Acta 
1969, 176, 463-470, doi:10.1016/0005-2760(69)90213-6.

3. Little, C.; Olinescu, R.; Reid, K.G.; O’Brien, P.J. Properties and Regulation of Glutathione Peroxidase. J. Biol. Chem. 1970, 245, 3632-3636.

4. Flohe, L.; Günzler, W.A.; Schock, H.H. Glutathione Peroxidase: A Selenoenzyme. FEBS Lett. 1973, 32, 132-134, doi:10.1016/0014-5793(73)80755-0.

5. Flohé, L. [Glutathione peroxidase: enzymology and biological aspects]. Klin. Wochenschr. 1971, 49, 669-683, doi:10.1007/BF01487101.

6. Forstrom, J.W.; Zakowski, J.J.; Tappel, A.L. Identification of the Catalytic Site of Rat Liver Glutathione Peroxidase as Selenocysteine. Biochemistry 1978, 17, 2639-2644, doi:10.1021/bi00606a028.

7. Rotruck, J.T.; Pope, A.L.; Ganther, H.E.; Swanson, A.B.; Hafeman, D.G.; Hoekstra, W.G. Selenium: Biochemical Role as a Component of Glutathione Peroxidase. Science 1973, 179, 588-590, doi:10.1126/science.179.4073.588.

8. Brigelius-Flohé, R.; Maiorino, M. Glutathione Peroxidases. Biochim. Biophys. Acta 2013, 1830, 3289-3303, doi:10.1016/j.bbagen.2012.11.020.

9. Trenz, T.S.; Delaix, C.L.; Turchetto-Zolet, A.C.; Zamocky, M.; Lazzarotto, F.; Margis-Pinheiro, M. Going Forward and Back: The Complex Evolutionary History of the GPx. Biology 2021, 10, 1165, doi:10.3390/biology10111165.

10. Margis, R.; Dunand, C.; Teixeira, F.K.; Margis-Pinheiro, M. Glutathione Peroxidase Family - an Evolutionary Overview. FEBS J. 2008, 275, 3959-3970, doi:10.1111/j.1742-4658.2008.06542.x.

11. Takebe, G.; Yarimizu, J.; Saito, Y.; Hayashi, T.; Nakamura, H.; Yodoi, J.; Nagasawa, S.; Takahashi, K. A Comparative Study on the Hydroperoxide and Thiol Specificity of the Glutathione Peroxidase Family and Selenoprotein P. J. Biol. Chem. 2002, 277, 41254-41258, doi:10.1074/jbc.M202773200.

12. Bersweiler, A.; D’Autréaux, B.; Mazon, H.; Kriznik, A.; Belli, G.; Delaunay-Moisan, A.; Toledano, M.B.; Rahuel-Clermont, S. A Scaffold Protein That Chaperones a Cysteine-Sulfenic Acid in H2O2 Signaling. Nat. Chem. Biol. 2017, 13, 909-915, doi:10.1038/nchembio.2412.

13. Brigelius-Flohé, R.; Flohé, L. Regulatory Phenomena in the Glutathione Peroxidase Superfamily. Antioxid. Redox Signal. 2020, 33, 498-516, doi:10.1089/ars.2019.7905.

14. Hatfield, D.L.; Tsuji, P.A.; Carlson, B.A.; Gladyshev, V.N. Selenium and Selenocysteine: Roles in Cancer, Health, and Development. Trends Biochem. Sci. 2014, 39, 112-120, doi:10.1016/j.tibs.2013.12.007.

15. Peng, J.-J.; Yue, S.-Y.; Fang, Y.-H.; Liu, X.-L.; Wang, C.-H. Mechanisms Affecting the Biosynthesis and Incorporation Rate of Selenocysteine. Mol. Basel Switz. 2021, 26, 7120, doi:10.3390/molecules26237120.

16. Friedmann Angeli, J.P.; Conrad, M. Selenium and GPX4, a Vital Symbiosis. Free Radic. Biol. Med. 2018, 127, 153-159, doi:10.1016/j.freeradbiomed.2018.03.001.

17. Lothrop, A.P.; Snider, G.W.; Ruggles, E.L.; Hondal, R.J. Why Is Mammalian Thioredoxin Reductase 1 so Dependent upon the Use of Selenium? Biochemistry 2014, 53, 554-565, doi:10.1021/bi400651x.

18. Areti, S.; Verma, S.K.; Bellare, J.; Rao, C.P. Selenocysteine vs Cysteine: Tuning the Derivatization on Benzenesulfonyl Moiety of a Triazole Linked Dansyl Connected Glycoconjugate for Selective Recognition of Selenocysteine and the Applicability of the Conjugate in Buffer, in Serum, on Silica Gel, and in HepG2 Cells. Anal. Chem. 2016, 88, 7259-7267, doi:10.1021/acs.analchem.6b01518.

19. Arnér, E.S.J. Selenoproteins-What Unique Properties Can Arise with Selenocysteine in Place of Cysteine? Exp. Cell Res. 2010, 316, 1296-1303, doi:10.1016/j.yexcr.2010.02.032.

20. Reich, H.J.; Hondal, R.J. Why Nature Chose Selenium. ACS Chem. Biol. 2016, 11, 821-841, doi:10.1021/acschembio.6b00031.

21. Maiorino, M.; Aumann, K.D.; Brigelius-Flohé, R.; Doria, D.; van den Heuvel, J.; McCarthy, J.; Roveri, A.; Ursini, F.; Flohé, L. Probing the Presumed Catalytic Triad of a Selenium-Containing Peroxidase by Mutational Analysis. Z. Ernahrungswiss. 
1998, 37 Suppl 1, 118-121.

22. Ingold, I.; Berndt, C.; Schmitt, S.; Doll, S.; Poschmann, G.; Buday, K.; Roveri, A.; Peng, X.; Porto Freitas, F.; Seibt, T.; et al. Selenium Utilization by GPX4 Is Required to Prevent Hydroperoxide-Induced Ferroptosis. Cell 2018, 172, 409-422.e21, doi:10.1016/j.cell.2017.11.048.

23. Hariharan, S.; Dharmaraj, S. Selenium and Selenoproteins: It's Role in Regulation of Inflammation. Inflammopharmacology 2020, 28, 667-695, doi:10.1007/s10787-020-00690-х.

24. Labunskyy, V.M.; Hatfield, D.L.; Gladyshev, V.N. Selenoproteins: Molecular Pathways and Physiological Roles. Physiol. Rev. 2014, 94, 739-777, doi:10.1152/physrev.00039.2013.

25. Kalimuthu, K.; Keerthana, C.K.; Mohan, M.; Arivalagan, J.; Christyraj, J.R.S.S.; Firer, M.A.; Choudry, M.H.A.; Anto, R.J.; Lee, Y.J. The Emerging Role of Selenium Metabolic Pathways in Cancer: New Therapeutic Targets for Cancer. J. Cell. Biochem. 2021, doi:10.1002/jcb.30196.

26. Shreenath, A.P.; Ameer, M.A.; Dooley, J. Selenium Deficiency. In StatPearls; StatPearls Publishing: Treasure Island (FL), 2021.

27. Rayman, M.P. Selenium Intake, Status, and Health: A Complex Relationship. Horm. Athens Greece 2020, 19, 9-14, doi:10.1007/s42000-019-00125-5.

28. Chen, J.; Berry, M.J. Selenium and Selenoproteins in the Brain and Brain Diseases. J. Neurochem. 2003, 86, 1-12, doi:10.1046/j.1471-4159.2003.01854.X.

29. Zhang, Y.; Zhou, Y.; Schweizer, U.; Savaskan, N.E.; Hua, D.; Kipnis, J.; Hatfield, D.L.; Gladyshev, V.N. Comparative Analysis of Selenocysteine Machinery and Selenoproteome Gene Expression in Mouse Brain Identifies Neurons as Key Functional Sites of Selenium in Mammals. J. Biol. Chem. 2008, 283, 2427-2438, doi:10.1074/jbc.M707951200.

30. Zhang, Z.-H.; Song, G.-L. Roles of Selenoproteins in Brain Function and the Potential Mechanism of Selenium in Alzheimer's Disease. Front. Neurosci. 2021, 15, 646518, doi:10.3389/fnins.2021.646518.

31. Janowski, R.; Scanu, S.; Niessing, D.; Madl, T. Crystal and Solution Structural Studies of Mouse Phospholipid Hydroperoxide Glutathione Peroxidase 4. Acta Crystallogr. Sect. F Struct. Biol. Commun. 2016, 72, 743-749, doi:10.1107/S2053230X16013686.

32. Labrecque, C.L.; Fuglestad, B. Electrostatic Drivers of GPx4 Interactions with Membrane, Lipids, and DNA. Biochemistry 2021, 60, 2761-2772, doi:10.1021/acs.biochem.1c00492.

33. Forcina, G.C.; Dixon, S.J. GPX4 at the Crossroads of Lipid Homeostasis and Ferroptosis. Proteomics 2019, 19, e1800311, doi:10.1002/pmic.201800311.

34. Ursini, F.; Maiorino, M. Lipid Peroxidation and Ferroptosis: The Role of GSH and GPx4. Free Radic. Biol. Med. 2020, 152, 175-185, doi:10.1016/j.freeradbiomed.2020.02.027.

35. Brieger, K.; Schiavone, S.; Miller, F.J.; Krause, K.-H. Reactive Oxygen Species: From Health to Disease. Swiss Med. Wkly. 2012, 142, w13659, doi:10.4414/smw.2012.13659.

36. Chen, Z.; Zhong, C. Oxidative Stress in Alzheimer's Disease. Neurosci. Bull. 2014, 30, 271-281, doi:10.1007/s12264-013$1423-\mathrm{y}$.

37. He, J.; Zhu, G.; Wang, G.; Zhang, F. Oxidative Stress and Neuroinflammation Potentiate Each Other to Promote Progression of Dopamine Neurodegeneration. Oxid. Med. Cell. Longev. 2020, 2020, 6137521, doi:10.1155/2020/6137521.

38. Kirtonia, A.; Sethi, G.; Garg, M. The Multifaceted Role of Reactive Oxygen Species in Tumorigenesis. Cell. Mol. Life Sci. CMLS 2020, 77, 4459-4483, doi:10.1007/s00018-020-03536-5.

39. Klaunig, J.E. Oxidative Stress and Cancer. Curr. Pharm. Des. 2018, 24, 4771-4778, doi:10.2174/1381612825666190215121712.

40. Zhang, P.; Li, T.; Wu, X.; Nice, E.C.; Huang, C.; Zhang, Y. Oxidative Stress and Diabetes: Antioxidative Strategies. Front. Med. 2020, 14, 583-600, doi:10.1007/s11684-019-0729-1. 
41. Sinha, N.; Dabla, P.K. Oxidative Stress and Antioxidants in Hypertension-a Current Review. Curr. Hypertens. Rev. 2015, 11, 132-142, doi:10.2174/1573402111666150529130922.

42. Zhang, Y.; Xin, L.; Xiang, M.; Shang, C.; Wang, Y.; Wang, Y.; Cui, X.; Lu, Y. The Molecular Mechanisms of Ferroptosis and Its Role in Cardiovascular Disease. Biomed. Pharmacother. Biomedecine Pharmacother. 2022, 145, 112423, doi:10.1016/j.biopha.2021.112423.

43. McClung, J.P.; Roneker, C.A.; Mu, W.; Lisk, D.J.; Langlais, P.; Liu, F.; Lei, X.G. Development of Insulin Resistance and Obesity in Mice Overexpressing Cellular Glutathione Peroxidase. Proc. Natl. Acad. Sci. U. S. A. 2004, 101, 8852-8857, doi:10.1073/pnas.0308096101.

44. Brigelius-Flohé, R.; Kipp, A. Glutathione Peroxidases in Different Stages of Carcinogenesis. Biochim. Biophys. Acta 2009, 1790, 1555-1568, doi:10.1016/j.bbagen.2009.03.006.

45. Brigelius-Flohé, R.; Kipp, A.P. Physiological Functions of GPx2 and Its Role in Inflammation-Triggered Carcinogenesis. Ann. N. Y. Acad. Sci. 2012, 1259, 19-25, doi:10.1111/j.1749-6632.2012.06574.x.

46. Florian, S.; Krehl, S.; Loewinger, M.; Kipp, A.; Banning, A.; Esworthy, S.; Chu, F.-F.; Brigelius-Flohé, R. Loss of GPx2 Increases Apoptosis, Mitosis, and GPx1 Expression in the Intestine of Mice. Free Radic. Biol. Med. 2010, 49, 1694, doi:10.1016/j.freeradbiomed.2010.08.029.

47. Naiki, T.; Naiki-Ito, A.; Iida, K.; Etani, T.; Kato, H.; Suzuki, S.; Yamashita, Y.; Kawai, N.; Yasui, T.; Takahashi, S. GPX2 Promotes Development of Bladder Cancer with Squamous Cell Differentiation through the Control of Apoptosis. Oncotarget 2018, 9, 15847, doi:10.18632/oncotarget.24627.

48. An, B.C.; Jung, N.-K.; Park, C.Y.; Oh, I.-J.; Choi, Y.-D.; Park, J.-I.; Lee, S.-W. Epigenetic and Glucocorticoid ReceptorMediated Regulation of Glutathione Peroxidase 3 in Lung Cancer Cells. Mol. Cells 2016, 39, 631-638, doi:10.14348/molcells.2016.0164.

49. Wang, H.; Luo, K.; Tan, L.-Z.; Ren, B.-G.; Gu, L.-Q.; Michalopoulos, G.; Luo, J.-H.; Yu, Y.P. P53-Induced Gene 3 Mediates Cell Death Induced by Glutathione Peroxidase 3. J. Biol. Chem. 2012, 287, 16890, doi:10.1074/jbc.M111.322636.

50. Yang, W.S.; SriRamaratnam, R.; Welsch, M.E.; Shimada, K.; Skouta, R.; Viswanathan, V.S.; Cheah, J.H.; Clemons, P.A.; Shamji, A.F.; Clish, C.B.; et al. Regulation of Ferroptotic Cancer Cell Death by GPX4. Cell 2014, 156, 317-331, doi:10.1016/j.cell.2013.12.010.

51. Ingold, I.; Aichler, M.; Yefremova, E.; Roveri, A.; Buday, K.; Doll, S.; Tasdemir, A.; Hoffard, N.; Wurst, W.; Walch, A.; et al. Expression of a Catalytically Inactive Mutant Form of Glutathione Peroxidase 4 (Gpx4) Confers a Dominant-Negative Effect in Male Fertility. J. Biol. Chem. 2015, 290, 14668-14678, doi:10.1074/jbc.M115.656363.

52. Chabory, E.; Damon, C.; Lenoir, A.; Kauselmann, G.; Kern, H.; Zevnik, B.; Garrel, C.; Saez, F.; Cadet, R.; Henry-Berger, J.; et al. Epididymis Seleno-Independent Glutathione Peroxidase 5 Maintains Sperm DNA Integrity in Mice. J. Clin. Invest. 2009, 119, 2074, doi:10.1172/JCI38940.

53. Eshraghi, M.; Karunadharma, P.P.; Blin, J.; Shahani, N.; Ricci, E.P.; Michel, A.; Urban, N.T.; Galli, N.; Sharma, M.; Ramírez-Jarquín, U.N.; et al. Mutant Huntingtin Stalls Ribosomes and Represses Protein Synthesis in a Cellular Model of Huntington Disease. Nat. Commun. 2021, 12, 1461, doi:10.1038/s41467-021-21637-y.

54. Nguyen, V.D.; Saaranen, M.J.; Karala, A.-R.; Lappi, A.-K.; Wang, L.; Raykhel, I.B.; Alanen, H.I.; Salo, K.E.H.; Wang, C.C.; Ruddock, L.W. Two Endoplasmic Reticulum PDI Peroxidases Increase the Efficiency of the Use of Peroxide during Disulfide Bond Formation. J. Mol. Biol. 2011, 406, 503-515, doi:10.1016/j.jmb.2010.12.039.

55. Ramming, T.; Appenzeller-Herzog, C. Destroy and Exploit: Catalyzed Removal of Hydroperoxides from the Endoplasmic Reticulum. Int. J. Cell Biol. 2013, 2013, 180906, doi:10.1155/2013/180906.

56. Ursini, F.; Maiorino, M.; Valente, M.; Ferri, L.; Gregolin, C. Purification from Pig Liver of a Protein Which Protects Liposomes and Biomembranes from Peroxidative Degradation and Exhibits Glutathione Peroxidase Activity on Phosphatidylcholine Hydroperoxides. Biochim. Biophys. Acta 1982, 710, 197-211, doi:10.1016/0005-2760(82)90150-3. 
57. Ursini, F.; Maiorino, M.; Gregolin, C. The Selenoenzyme Phospholipid Hydroperoxide Glutathione Peroxidase. Biochim. Biophys. Acta 1985, 839, 62-70, doi:10.1016/0304-4165(85)90182-5.

58. Schuckelt, R.; Brigelius-Flohé, R.; Maiorino, M.; Roveri, A.; Reumkens, J.; Strabburger, W.; Ursini, F.; Wolf, B.; Flohé, L. Phospholipid Hydroperoxide Glutathione Peroxidase Is a Seleno-Enzyme Distinct from the Classical Glutathione Peroxidase as Evident from Cdna and Amino Acid Sequencing. Free Radic. Res. Commun. 1991, 14, 343-361, doi:10.3109/10715769109093424.

59. Liu, H.; Forouhar, F.; Seibt, T.; Saneto, R.; Wigby, K.; Friedman, J.; Xia, X.; Shchepinov, M.S.; Ramesh, S.K.; Conrad, M.; et al. Characterization of a Patient-Derived Variant of GPX4 for Precision Therapy. Nat. Chem. Biol. 2022, 18, 91-100, doi:10.1038/s41589-021-00915-2.

60. Conrad, M.; Schneider, M.; Seiler, A.; Bornkamm, G.W. Physiological Role of Phospholipid Hydroperoxide Glutathione Peroxidase in Mammals. Biol. Chem. 2007, 388, 1019-1025, doi:10.1515/BC.2007.130.

61. Godeas, C.; Tramer, F.; Micali, F.; Roveri, A.; Maiorino, M.; Nisii, C.; Sandri, G.; Panfili, E. Phospholipid Hydroperoxide Glutathione Peroxidase (PHGPx) in Rat Testis Nuclei Is Bound to Chromatin. Biochem. Mol. Med. 1996, 59, 118-124, doi:10.1006/bmme.1996.0076.

62. Maiorino, M.; Roveri, A.; Benazzi, L.; Bosello, V.; Mauri, P.; Toppo, S.; Tosatto, S.C.E.; Ursini, F. Functional Interaction of Phospholipid Hydroperoxide Glutathione Peroxidase with Sperm Mitochondrion-Associated Cysteine-Rich Protein Discloses the Adjacent Cysteine Motif as a New Substrate of the Selenoperoxidase. J. Biol. Chem. 2005, 280, 38395-38402, doi:10.1074/jbc.M505983200.

63. Friedmann Angeli, J.P.; Schneider, M.; Proneth, B.; Tyurina, Y.Y.; Tyurin, V.A.; Hammond, V.J.; Herbach, N.; Aichler, M.; Walch, A.; Eggenhofer, E.; et al. Inactivation of the Ferroptosis Regulator Gpx4 Triggers Acute Renal Failure in Mice. Nat. Cell Biol. 2014, 16, 1180-1191, doi:10.1038/ncb3064.

64. Yant, L.J.; Ran, Q.; Rao, L.; Van Remmen, H.; Shibatani, T.; Belter, J.G.; Motta, L.; Richardson, A.; Prolla, T.A. The Selenoprotein GPX4 Is Essential for Mouse Development and Protects from Radiation and Oxidative Damage Insults. Free Radic. Biol. Med. 2003, 34, 496-502, doi:10.1016/s0891-5849(02)01360-6.

65. Hangauer, M.J.; Viswanathan, V.S.; Ryan, M.J.; Bole, D.; Eaton, J.K.; Matov, A.; Galeas, J.; Dhruv, H.D.; Berens, M.E.; Schreiber, S.L.; et al. Drug-Tolerant Persister Cancer Cells Are Vulnerable to GPX4 Inhibition. Nature 2017, 551, 247-250, doi:10.1038/nature24297.

66. Song, X.; Wang, X.; Liu, Z.; Yu, Z. Role of GPX4-Mediated Ferroptosis in the Sensitivity of Triple Negative Breast Cancer Cells to Gefitinib. Front. Oncol. 2020, 10, 597434, doi:10.3389/fonc.2020.597434.

67. da Rocha, T.J.; Silva Alves, M.; Guisso, C.C.; de Andrade, F.M.; Camozzato, A.; de Oliveira, A.A.; Fiegenbaum, M. Association of GPX1 and GPX4 Polymorphisms with Episodic Memory and Alzheimer's Disease. Neurosci. Lett. 2018, 666, 32-37, doi:10.1016/j.neulet.2017.12.026.

68. Hambright, W.S.; Fonseca, R.S.; Chen, L.; Na, R.; Ran, Q. Ablation of Ferroptosis Regulator Glutathione Peroxidase 4 in Forebrain Neurons Promotes Cognitive Impairment and Neurodegeneration. Redox Biol. 2017, 12, 8-17, doi:10.1016/j.redox.2017.01.021.

69. Jakaria, M.; Belaidi, A.A.; Bush, A.I.; Ayton, S. Ferroptosis as a Mechanism of Neurodegeneration in Alzheimer's Disease. J. Neurochem. 2021, 159, 804-825, doi:10.1111/jnc.15519.

70. Fallahi, S.; Rajaei, M.; Hesam, M.J.; Koolivand, M.; Malekzadeh, K. The Effect of Phoenix Dactylifera Pollen on the Expression of NRF2, SOD2, CAT, and GPX4 Genes, and Sperm Parameters of Fertile and Infertile Men: A Controlled Clinical Trial. Int. J. Reprod. Biomed. 2021, 19, 545-558, doi:10.18502/ijrm.v19i6.9376.

71. Borchert, A.; Kalms, J.; Roth, S.R.; Rademacher, M.; Schmidt, A.; Holzhutter, H.-G.; Kuhn, H.; Scheerer, P. Crystal Structure and Functional Characterization of Selenocysteine-Containing Glutathione Peroxidase 4 Suggests an Alternative Mechanism of Peroxide Reduction. Biochim. Biophys. Acta Mol. Cell Biol. Lipids 2018, 1863, 1095-1107, 
doi:10.1016/j.bbalip.2018.06.006.

72. Tosatto, S.C.E.; Bosello, V.; Fogolari, F.; Mauri, P.; Roveri, A.; Toppo, S.; Flohé, L.; Ursini, F.; Maiorino, M. The Catalytic Site of Glutathione Peroxidases. Antioxid. Redox Signal. 2008, 10, 1515-1526, doi:10.1089/ars.2008.2055.

73. Peeler, J.C.; Weerapana, E. Chemical Biology Approaches to Interrogate the Selenoproteome. Acc. Chem. Res. 2019, 52, 2832-2840, doi:10.1021/acs.accounts.9b00379.

74. Scheerer, P.; Borchert, A.; Krauss, N.; Wessner, H.; Gerth, C.; Höhne, W.; Kuhn, H. Structural Basis for Catalytic Activity and Enzyme Polymerization of Phospholipid Hydroperoxide Glutathione Peroxidase-4 (GPx4). Biochemistry 2007, 46, 9041-9049, doi:10.1021/bi700840d.

75. Eaton, J.K.; Furst, L.; Ruberto, R.A.; Moosmayer, D.; Hilpmann, A.; Ryan, M.J.; Zimmermann, K.; Cai, L.L.; Niehues, M.; Badock, V.; et al. Selective Covalent Targeting of GPX4 Using Masked Nitrile-Oxide Electrophiles. Nat. Chem. Biol. 2020, 16, 497-506, doi:10.1038/s41589-020-0501-5.

76. Bjørklund, G.; Tinkov, A.A.; Hosnedlová, B.; Kizek, R.; Ajsuvakova, O.P.; Chirumbolo, S.; Skalnaya, M.G.; Peana, M.; Dadar, M.; El-Ansary, A.; et al. The Role of Glutathione Redox Imbalance in Autism Spectrum Disorder: A Review. Free Radic. Biol. Med. 2020, 160, 149-162, doi:10.1016/j.freeradbiomed.2020.07.017.

77. Kennedy, L.; Sandhu, J.K.; Harper, M.-E.; Cuperlovic-Culf, M. Role of Glutathione in Cancer: From Mechanisms to Therapies. Biomolecules 2020, 10, E1429, doi:10.3390/biom10101429.

78. Wrotek, S.; Sobocińska, J.; Kozłowski, H.M.; Pawlikowska, M.; Jędrzejewski, T.; Dzialuk, A. New Insights into the Role of Glutathione in the Mechanism of Fever. Int. J. Mol. Sci. 2020, 21, E1393, doi:10.3390/ijms21041393.

79. Teskey, G.; Abrahem, R.; Cao, R.; Gyurjian, K.; Islamoglu, H.; Lucero, M.; Martinez, A.; Paredes, E.; Salaiz, O.; Robinson, B.; et al. Glutathione as a Marker for Human Disease. Adv. Clin. Chem. 2018, 87, 141-159, doi:10.1016/bs.acc.2018.07.004.

80. Forman, H.J.; Zhang, H.; Rinna, A. Glutathione: Overview of Its Protective Roles, Measurement, and Biosynthesis. Mol. Aspects Med. 2009, 30, 1-12, doi:10.1016/j.mam.2008.08.006.

81. Zhu, S.; Zhang, Q.; Sun, X.; Zeh, H.J.; Lotze, M.T.; Kang, R.; Tang, D. HSPA5 Regulates Ferroptotic Cell Death in Cancer Cells. Cancer Res. 2017, 77, 2064-2077, doi:10.1158/0008-5472.CAN-16-1979.

82. Tang, D.; Kang, R.; Berghe, T.V.; Vandenabeele, P.; Kroemer, G. The Molecular Machinery of Regulated Cell Death. Cell Res. 2019, 29, 347, doi:10.1038/s41422-019-0164-5.

83. Kerr, J.F.R.; Wyllie, A.H.; Currie, A.R. Apoptosis: A Basic Biological Phenomenon with Wide-Ranging Implications in Tissue Kinetics. Br. J. Cancer 1972, 26, 239, doi:10.1038/bjc.1972.33.

84. D'Arcy, M.S. Cell Death: A Review of the Major Forms of Apoptosis, Necrosis and Autophagy. Cell Biol. Int. 2019, 43, 582-592, doi:10.1002/cbin.11137.

85. Ko, C.-J.; Gao, S.-L.; Lin, T.-K.; Chu, P.-Y.; Lin, H.-Y. Ferroptosis as a Major Factor and Therapeutic Target for Neuroinflammation in Parkinson's Disease. Biomedicines 2021, 9, 1679, doi:10.3390/biomedicines9111679.

86. Mahoney-Sánchez, L.; Bouchaoui, H.; Ayton, S.; Devos, D.; Duce, J.A.; Devedjian, J.-C. Ferroptosis and Its Potential Role in the Physiopathology of Parkinson's Disease. Prog. Neurobiol. 2021, 196, 101890, doi:10.1016/j.pneurobio.2020.101890.

87. Mazhar, M.; Din, A.U.; Ali, H.; Yang, G.; Ren, W.; Wang, L.; Fan, X.; Yang, S. Implication of Ferroptosis in Aging. Cell Death Discov. 2021, 7, 149, doi:10.1038/s41420-021-00553-6.

88. Peña-Bautista, C.; Vento, M.; Baquero, M.; Cháfer-Pericás, C. Lipid Peroxidation in Neurodegeneration. Clin. Chim. Acta Int. J. Clin. Chem. 2019, 497, 178-188, doi:10.1016/j.cca.2019.07.037.

89. Ghoochani, A.; Hsu, E.-C.; Aslan, M.; Rice, M.A.; Nguyen, H.M.; Brooks, J.D.; Corey, E.; Paulmurugan, R.; Stoyanova, T. Ferroptosis Inducers Are a Novel Therapeutic Approach for Advanced Prostate Cancer. Cancer Res. 2021, 81, 15831594, doi:10.1158/0008-5472.CAN-20-3477.

90. Wu, S.; Zhu, C.; Tang, D.; Dou, Q.P.; Shen, J.; Chen, X. The Role of Ferroptosis in Lung Cancer. Biomark. Res. 2021, 9, 82, doi:10.1186/s40364-021-00338-0. 
91. Xu, W.; Deng, H.; Hu, S.; Zhang, Y.; Zheng, L.; Liu, M.; Chen, Y.; Wei, J.; Yang, H.; Lv, X. Role of Ferroptosis in Lung Diseases. J. Inflamm. Res. 2021, 14, 2079-2090, doi:10.2147/JIR.S307081.

92. Jiang, X.; Stockwell, B.R.; Conrad, M. Ferroptosis: Mechanisms, Biology and Role in Disease. Nat. Rev. Mol. Cell Biol. 2021, 22, 266-282, doi:10.1038/s41580-020-00324-8.

93. Stockwell, B.R.; Jiang, X.; Gu, W. Emerging Mechanisms and Disease Relevance of Ferroptosis. Trends Cell Biol. 2020, 30, 478-490, doi:10.1016/j.tcb.2020.02.009.

94. Eagle, H. Nutrition Needs of Mammalian Cells in Tissue Culture. Science 1955, 122, 501-514, doi:10.1126/science.122.3168.501.

95. Eagle, H.; Piez, K.A.; Oyama, V.I. The Biosynthesis of Cystine in Human Cell Cultures. J. Biol. Chem. 1961, 236, 14251428.

96. Mitchell, J.R.; Jollow, D.J.; Potter, W.Z.; Gillette, J.R.; Brodie, B.B. Acetaminophen-Induced Hepatic Necrosis. IV. Protective Role of Glutathione. J. Pharmacol. Exp. Ther. 1973, 187, 211-217.

97. Bannai, S.; Tsukeda, H.; Okumura, H. Effect of Antioxidants on Cultured Human Diploid Fibroblasts Exposed to CystineFree Medium. Biochem. Biophys. Res. Commun. 1977, 74, 1582-1588, doi:10.1016/0006-291x(77)90623-4.

98. Maher, P.; Currais, A.; Schubert, D. Using the Oxytosis/Ferroptosis Pathway to Understand and Treat Age-Associated Neurodegenerative Diseases. Cell Chem. Biol. 2020, 27, 1456-1471, doi:10.1016/j.chembiol.2020.10.010.

99. Murphy, T.H.; Miyamoto, M.; Sastre, A.; Schnaar, R.L.; Coyle, J.T. Glutamate Toxicity in a Neuronal Cell Line Involves Inhibition of Cystine Transport Leading to Oxidative Stress. Neuron 1989, 2, 1547-1558, doi:10.1016/08966273(89)90043-3.

100. Dixon, S.J.; Lemberg, K.M.; Lamprecht, M.R.; Skouta, R.; Zaitsev, E.M.; Gleason, C.E.; Patel, D.N.; Bauer, A.J.; Cantley, A.M.; Yang, W.S.; et al. Ferroptosis: An Iron-Dependent Form of Nonapoptotic Cell Death. Cell 2012, 149, 1060-1072, doi:10.1016/j.cell.2012.03.042.

101. Li, J.; Cao, F.; Yin, H.; Huang, Z.; Lin, Z.; Mao, N.; Sun, B.; Wang, G. Ferroptosis: Past, Present and Future. Cell Death Dis. 2020, 11, 1-13, doi:10.1038/s41419-020-2298-2.

102. Kim, S.-W.; Kim, Y.; Kim, S.E.; An, J.-Y. Ferroptosis-Related Genes in Neurodevelopment and Central Nervous System. Biology 2021, 10, doi:10.3390/biology10010035.

103. Zhuo, S.; Chen, Z.; Yang, Y.; Zhang, J.; Tang, J.; Yang, K. Clinical and Biological Significances of a Ferroptosis-Related Gene Signature in Glioma. Front. Oncol. 2020, 10, 590861, doi:10.3389/fonc.2020.590861.

104. Mandal, P.K.; Seiler, A.; Perisic, T.; Kölle, P.; Banjac Canak, A.; Förster, H.; Weiss, N.; Kremmer, E.; Lieberman, M.W.; Bannai, S.; et al. System Xc- and Thioredoxin Reductase 1 Cooperatively Rescue Glutathione Deficiency*. J. Biol. Chem. 2010, 285, 22244-22253, doi:10.1074/jbc.M110.121327.

105. Seibt, T.M.; Proneth, B.; Conrad, M. Role of GPX4 in Ferroptosis and Its Pharmacological Implication. Free Radic. Biol. Med. 2019, 133, 144-152, doi:10.1016/j.freeradbiomed.2018.09.014.

106. Xie, Y.; Zhu, S.; Song, X.; Sun, X.; Fan, Y.; Liu, J.; Zhong, M.; Yuan, H.; Zhang, L.; Billiar, T.R.; et al. The Tumor Suppressor P53 Limits Ferroptosis by Blocking DPP4 Activity. Cell Rep. 2017, 20, 1692-1704, doi:10.1016/j.celrep.2017.07.055.

107. Zhang, Y.; Shi, J.; Liu, X.; Feng, L.; Gong, Z.; Koppula, P.; Sirohi, K.; Li, X.; Wei, Y.; Lee, H.; et al. BAP1 Links Metabolic Regulation of Ferroptosis to Tumour Suppression. Nat. Cell Biol. 2018, 20, 1181-1192, doi:10.1038/s41556-018-0178-0.

108. Zheng, J.; Conrad, M. The Metabolic Underpinnings of Ferroptosis. Cell Metab. 2020, 32, 920-937, doi:10.1016/j.cmet.2020.10.011.

109. Shah, R.; Shchepinov, M.S.; Pratt, D.A. Resolving the Role of Lipoxygenases in the Initiation and Execution of Ferroptosis. ACS Cent. Sci. 2018, 4, 387-396, doi:10.1021/acscentsci.7b00589.

110. Wenzel, S.E.; Tyurina, Y.Y.; Zhao, J.; St Croix, C.M.; Dar, H.H.; Mao, G.; Tyurin, V.A.; Anthonymuthu, T.S.; Kapralov, 
A.A.; Amoscato, A.A.; et al. PEBP1 Wardens Ferroptosis by Enabling Lipoxygenase Generation of Lipid Death Signals. Cell 2017, 171, 628-641.e26, doi:10.1016/j.cell.2017.09.044.

111. Maiorino, M.; Conrad, M.; Ursini, F. GPx4, Lipid Peroxidation, and Cell Death: Discoveries, Rediscoveries, and Open Issues. Antioxid. Redox Signal. 2018, 29, 61-74, doi:10.1089/ars.2017.7115.

112. Seiler, A.; Schneider, M.; Förster, H.; Roth, S.; Wirth, E.K.; Culmsee, C.; Plesnila, N.; Kremmer, E.; Rådmark, O.; Wurst, W.; et al. Glutathione Peroxidase 4 Senses and Translates Oxidative Stress into 12/15-Lipoxygenase Dependent- and AIFMediated Cell Death. Cell Metab. 2008, 8, 237-248, doi:10.1016/j.cmet.2008.07.005.

113. Matsushita, M.; Freigang, S.; Schneider, C.; Conrad, M.; Bornkamm, G.W.; Kopf, M. T Cell Lipid Peroxidation Induces Ferroptosis and Prevents Immunity to Infection. J. Exp. Med. 2015, 212, 555-568, doi:10.1084/jem.20140857.

114. Imai, H.; Matsuoka, M.; Kumagai, T.; Sakamoto, T.; Koumura, T. Lipid Peroxidation-Dependent Cell Death Regulated by GPx4 and Ferroptosis. Curr. Top. Microbiol. Immunol. 2017, 403, 143-170,doi:10.1007/82_2016_508.

115. Pennington, L.D.; Muegge, I. Holistic Drug Design for Multiparameter Optimization in Modern Small Molecule Drug Discovery. Bioorg. Med. Chem. Lett. 2021, 41, 128003, doi:10.1016/j.bmcl.2021.128003.

116. Stockwell, B.R. Chemical Genetics: Ligand-Based Discovery of Gene Function. Nat. Rev. Genet. 2000, 1, 116-125, doi:10.1038/35038557.

117. Stockwell, B.R.; Jiang, X. The Chemistry and Biology of Ferroptosis. Cell Chem. Biol. 2020, 27, 365-375, doi:10.1016/j.chembiol.2020.03.013.

118. Viswanathan, V.S.; Ryan, M.J.; Dhruv, H.D.; Gill, S.; Eichhoff, O.M.; Seashore-Ludlow, B.; Kaffenberger, S.D.; Eaton, J.K.; Shimada, K.; Aguirre, A.J.; et al. Dependency of a Therapy-Resistant State of Cancer Cells on a Lipid Peroxidase Pathway. Nature 2017, 547, 453-457, doi:10.1038/nature23007.

119. Su, Y.; Zhao, B.; Zhou, L.; Zhang, Z.; Shen, Y.; Lv, H.; AlQudsy, L.H.H.; Shang, P. Ferroptosis, a Novel Pharmacological Mechanism of Anti-Cancer Drugs. Cancer Lett. 2020, 483, 127-136, doi:10.1016/j.canlet.2020.02.015.

120. Dolma, S.; Lessnick, S.L.; Hahn, W.C.; Stockwell, B.R. Identification of Genotype-Selective Antitumor Agents Using Synthetic Lethal Chemical Screening in Engineered Human Tumor Cells. Cancer Cell 2003, 3, 285-296, doi:10.1016/s1535-6108(03)00050-3.

121. Dixon, S.J.; Patel, D.N.; Welsch, M.; Skouta, R.; Lee, E.D.; Hayano, M.; Thomas, A.G.; Gleason, C.E.; Tatonetti, N.P.; Slusher, B.S.; et al. Pharmacological Inhibition of Cystine-Glutamate Exchange Induces Endoplasmic Reticulum Stress and Ferroptosis. eLife 2014, 3, e02523, doi:10.7554/eLife.02523.

122. Wei, Y.; Lv, H.; Shaikh, A.B.; Han, W.; Hou, H.; Zhang, Z.; Wang, S.; Shang, P. Directly Targeting Glutathione Peroxidase 4 May Be More Effective than Disrupting Glutathione on Ferroptosis-Based Cancer Therapy. Biochim. Biophys. Acta Gen. Subj. 2020, 1864, 129539, doi:10.1016/j.bbagen.2020.129539.

123. Yang, W.S.; Stockwell, B.R. Synthetic Lethal Screening Identifies Compounds Activating Iron-Dependent, Nonapoptotic Cell Death in Oncogenic-RAS-Harboring Cancer Cells. Chem. Biol. 2008, 15, 234-245, doi:10.1016/j.chembiol.2008.02.010.

124. Armenta, D.A.; Dixon, S.J. Investigating Nonapoptotic Cell Death Using Chemical Biology 2020, 27(4), 376-386, doi: 10.1016/j.chembiol.2020.03.005 